\title{
Prediction of Methyl Orange Removal by Iron Decorated Activated Carbon using an Artificial Neural Network
}

\author{
Shweta Mitra ${ }^{1}$, Tirthankar Mukherjee ${ }^{2}$ and Prasad Kaparaju ${ }^{3 *}$ \\ ${ }^{1}$ Department of Polymer Science and Technology, University of Calcutta, Kolkata, India \\ ${ }^{2}$ Department of Chemical Engineering, Jadavpur University, Kolkata, India \\ ${ }^{3}$ School of Engineering and Built Environment, Nathan Campus, Griffith University, Brisbane, \\ Australia. *p.kaparaju@griffith.edu.au
}

\begin{abstract}
Date Stones were used as a bio-degradable waste source for preparing iron impregnated activated carbon. The prepared activated carbon-containing oxides of iron were characterized using SEM, XRD, FTIR, and BET. The specific surface area of the iron decorated activated carbon was $738.65 \mathrm{~m}^{2} / \mathrm{g}$. The XRD confirmed the presence of magnetite and hematite while the SEM images assured the presence of pores. The prepared activated carbon was used to remove methyl orange from wastewater. Genetic Algorithm was used to develop a model which could predict the removal efficiency of the dye. The ANN model was validated and the effect of different parameters like adsorbent dosage (0.1-1g/L), initial dye concentration $(2-20 \mathrm{mg} / \mathrm{L}), \mathrm{pH}$ (2-11), time (10-55 minutes) and temperature $\left(30-75^{\circ} \mathrm{C}\right)$ was estimated both experimentally and predicted using the model. The adsorption process follows the Freundlich isotherm and pseudosecond-order kinetic model. The values of $1 / \mathrm{n}$ and $\mathrm{K}_{\mathrm{F}}$ obtained from the Freundlich isotherm designate good adsorption capacity. Both experimental and model-predicted data agrees with the kinetic model. The adsorption rate is proportionate to the square of the number of vacant adsorption sites. From the thermodynamic study, the positive worth of $\Delta \mathrm{H}^{\circ}$ indicates the energyabsorbing nature of the surface assimilation method and the process is endothermic in nature. The low values of each $\Delta \mathrm{G}^{\circ}(-200$ to $0 \mathrm{~kJ} / \mathrm{mol})$ and $\Delta \mathrm{H}^{\circ}$ correspond to physical surface assimilation. A positive worth of $\Delta \mathrm{S}^{\circ}$ reflects the inflated randomness at the solid-aqueous interface with some structural changes in adsorbate and adsorbent.
\end{abstract}

Keywords: activated carbon, artificial neural network, date stones, methyl orange, regression 


\section{Introduction}

Discharge of wastewater containing chemicals and dyes from industries such as textiles, paper, etc., is considered as a serious global problem due to aquatic and environmental pollution. Synthetic dyes are man-made chemicals that are extremely toxic and have a carcinogenic effect on humans and animals and will cause irreversible damage to the ecosystem, if released untreated in the environment (Tsuboy et al. 2007, Vinitnantharat et al. 2008). Therefore, it is necessary that these effluents are treated to an acceptable industry standard before being discharged into the environment. Methyl Orange (MO) is a common dye used in textile industries. It has been shown that MO is highly toxic and causes severe irritation of eyes and may lead to permanent ocular damage (Mitra and Mukherjee 2018). Treatment technologies such as adsorption, oxidation-ozonation, biological treatment, coagulation-flocculation, and membrane processes were shown to be used for the treatment of dye-containing effluents (Ghaedi et al. 2017). Among the above-mentioned methods, the adsorption process was proved to be the most commonly used method for dye removal due to its high efficiency, availability of different sorbent materials and easy handling.

Activated carbon is the most commonly used absorbent material and is found to be more effective in dye removal compared to other natural or synthetic adsorbents due to its large surface area, micro-porosity and high degrees of surface reactivity and adsorption capacity (Alslaibi et al. 2013). The process is a high-temperature application with wide-ranging $\mathrm{pH}$ and high porosity that increases adsorption capacity etc. (Noorimotlagh et al. 2016, Jaafarzadeh et al. 2019). Activated carbon impregnated with metal oxides increases catalytic oxidation and enhances adsorption capacities. However, activated carbon is expensive and therefore, it is necessary to find an alternative cheap and easily available adsorbent (Mirzaei et al. 2017). Agricultural wastes such as coconut shells, peanut shells, rice straw, sugarcane bagasse, rice husksetc.havebeen of great research interest due to its abundance and ability to biodegrade in nature benignly and can be disposed of without regeneration(Vinitnantharat et al. 2008, Alslaibi et al. 2013). The bio-sorption process is dependent on the availability of the functional groups such as carboxylic, phenolic, ether, cellulose, lignin, alcohols and aldehydes on the biosorbents (Qada et al. 2006).

Date palm (Phoenix dactylifera Linn) stones or pits are the leftover waste products obtained from the Date processing industries. These stones or pits contain about $47.14 \%$ carbon 
and have been used to produce commercially feasible adsorbent for removal of dye in wastewaters (Ghouti et al. 2010, Ozbelge et al. 2002, Pasalari et al. 2017). If a theoretical prediction model is developed it can be used to obtain reasonable estimates of the adsorption of dye at different parameter value which can be obtained by using different statistical and learning procedures, like multiple linear regression (MLR), artificial neural network (ANN), partial least square (PLS), etc. (Ghaedi et al. 2011). Among the modeling tools, ANN has recently become a very efficient and popular modeling tool. It is an information processing tool that can establish a relationship between input and output data by extracting information presented to the network. The major advantage of ANN is its ability to use and solve nonlinear relationships and thereby predict adsorption accurately (Mukherjee et al. 2018, Mukherjee and Rahaman 2018, Roosta et al. 2014, Kalyanmoy 1996).

Thus, a model predicting the removal of MO dye using activated carbon obtained from biodegradable waste (Date stones) has not been reported to that extent. This research focuses on the production of value-added products for the treatment of wastewater and also developing a prediction model using Artificial Neural Network. In this study, the adsorption behavior of Date stone activated carbon impregnated with iron particles for the removal of MO dye from aqueous solution was investigated. The impregnated activated carbon can be separated from the wastewater using an external magnet source (Nia et al. 2014). This prevents the loss of produced activated carbon and its easy separation from the solution. Different parameters such as $\mathrm{pH}$, adsorbent dosage $(\mathrm{g} / \mathrm{L})$, the initial concentration of dye $(\mathrm{mg} / \mathrm{L})$ and temperature $\left({ }^{\circ} \mathrm{C}\right)$ were studied by using ANN. Freundlich isotherm and Langmuir isotherm models were used to describing the experimental sorption data (Karimi et al. 2014). Finally, the mechanism of biosorption was elucidated by using pseudo-first-order and second-order kinetic models.

\section{Materials and Methods}

\subsection{Feedstock}

Date stones (DS) were collected from a local dry fruit vendor. The stones were washed and dried at room temperature prior to use.

\subsection{Materials and Measurements}


For laboratory experiments, analytical grade chemical reagents were sourced from Sigma-Aldrich, Bhupendra Shah \& Co., Kolkata, India. Iron Sulphate Heptahydrate $\left(\mathrm{Fe}_{2} \mathrm{SO}_{4}\right.$, $\left.7 \mathrm{H}_{2} \mathrm{O}\right)$ was used for iron impregnation. Potassium Hydroxide $(\mathrm{KOH}), 37 \%$ hydrochloric acid $(\mathrm{HCl})$, Sodium Hydroxide $(\mathrm{NaOH})$ were used for the $\mathrm{pH}$ adjustment. Methyl Orange (MO) was purchased from Hexon Laboratories, Mumbai, India. All reagents were used without further purification.

For the determination of the removal efficiency of the MO solution, UV-visible spectrophotometer (LMSP UV1000B) was used. The morphological studies were carried out using Scanning electron microscopy (SEM) (ZEISS EVO-MA). The scan settings were fixed at an emission current of $100 \mathrm{~mA}$ and an accelerator voltage of $10 \mathrm{kV}$. The diffraction patterns of the prepared activated carbon were analyzed using an XRD performed with Pananalytical PW 3040/60 X'pert Pro-powder diffractometer. ASAP 2020 MICROMIRITICS was used to measure the specific surface area and to characterize the pore structure of the activated carbons. Chemical characterization was carried out by FTIR spectroscopy in order to identify the functional groups

at the surface of DSAC using Thermo Nicolet Nexus 870 FTIR instrument in the region of 400 $4000 \mathrm{~cm}^{-1}$. The samples were prepared as $\mathrm{KBr}$ pellets, comprised of a $1 \mathrm{mg}$ sample of dried DSAC and $100 \mathrm{mg}$ ground $\mathrm{KBr}$.

\subsection{Preparation of Date Stone Activated Carbon (DSAC)}

Dust particles were removed by thoroughly by washing the DS. Later, DS was dried at 85 ${ }^{\circ} \mathrm{C}$ for 24 hours in a hot air oven. The dried DS was then carbonized at $400{ }^{\circ} \mathrm{C}$ for 2 hours in a muffle furnace. The carbonized Date stones (CDS) were then passed through a $250 \mu \mathrm{m}$ mesh $(0.250 \mathrm{~mm})$. The fine particles collected thus were then chemically treated with $5 \% \mathrm{KOH}$. The ratio of $\mathrm{KOH}$ solution and CDSwas kept at a 2:1 ratio. Activation was progressed for 12 hours and then it was thoroughly washed to make it neutral. Partially activated carbon was again dried in a hot air oven for 24 hours and then the dried material was put into muffle furnace for further carbonization at $700^{\circ} \mathrm{C}$ for 2 hours.

\subsection{Preparation of iron impregnated DSAC (DSAC/Fe)}

DSAC was precisely weighed in a requisite amount $(1: 5(\mathrm{w} / \mathrm{w})$ ratio)and mixed with iron salt $\left(\mathrm{Fe}_{2} \mathrm{SO}_{4}, 7 \mathrm{H}_{2} \mathrm{O}\right)$. The solution was agitated and heated to $100{ }^{\circ} \mathrm{C}$ for 2 hours using a 
magnetic stirrer. The hydrated iron oxides were precipitated using $10 \% \mathrm{NaOH}$ solution. Lastly, the Fe impregnated DSAC product (DSAC/Fe) was carefully washed with excess water to neutralize it. Then it was dried for storage. The final product was approximately spherical in shape with a diameter of around $0.090 \mathrm{~mm}$.

\subsection{Experimental set-up}

All experiments were performed in batch mode. For each batch, $100 \mathrm{ml}$ of an aqueous solution of MO dye was transferred to a flask. Temperature controlled magnetic stirrer was used to ensure proper mixing. Reactor contents were mixed at a mixing speed of $350 \mathrm{rpm}$ and were kept constant for all the experiments. Initial concentrations of the dye solution were varied in the experiments. At acidic conditions the removal efficiency is maximum (Refer to section: 3.3.1.) and hence, the preliminary $\mathrm{pH}$ of the solution was kept constant at $2 \mathrm{pH}$ by adding $0.1 \mathrm{M} \mathrm{HCl}$ and $0.1 \mathrm{M} \mathrm{NaOH}$ solution before DSAC/Fe was added. A pre-determined amount of activated carbon was used here. After a fixed amount of time elapsed (300 minutes), the solution was filtered. UV-Visible Spectrophotometer at a wavelength of $463 \mathrm{~nm}$ was used to obtain the final MO solution concentration. The amount of adsorption at equilibrium or the adsorption capacity $\left(\mathrm{q}_{\mathrm{e}}\right)$ was calculated using equation 1 (Karimi et al. 2014):

$q_{e}=\left(C_{o}-C_{e}\right) \times \frac{V}{W}$

where, $\mathrm{C}_{0}$ and $\mathrm{C}_{\mathrm{e}}(\mathrm{mg} / \mathrm{L})$ are the concentrations of the $\mathrm{MO}$ dye in solution initially and at equilibrium respectively, while $\mathrm{V}$ is the solution volume $(\mathrm{L})$ and $\mathrm{W}$ is the mass of adsorbent used (g). The percentage removal of dye was determined using equation 2:

Removal Efficiency $=\frac{\mathrm{C}_{\mathrm{i}}-\mathrm{C}_{\mathrm{f}}}{\mathrm{C}_{\mathrm{i}}} \times 100$

Where, $\mathrm{C}_{\mathrm{i}}$ and $\mathrm{C}_{f}$ are the initial and final concentrations of the MO solution, respectively.

\subsection{Isotherm and Kinetics of Adsorption}

Designing and choosing the finest operating conditions for a full-scale batch process, the prediction of the adsorption rate offers important information. Adsorption kinetics and isotherms 
deliver valuable data about the mechanism of the reactions, the reaction pathways, and the mechanisms governing the adsorption routes, such as mass transfer (Karimi et al. 2014; Zeinali et al. 2014).

\subsubsection{Langmuir Isotherm}

The Langmuir isotherm assumes simple monolayer adsorption onto an adsorbent surface comprising of a finite number of adsorption sites. There is no lateral interaction between the dye molecules and no migration of adsorbate in the same plane. Moreover, the model assumes only a fixed number of energetically invariant active sites. The Langmuir isotherm in its linear form is shown in equation 3 (Kakavandi et al. 2014):

$\frac{C_{e}}{q_{e}}=\frac{1}{Q_{0} b}+\frac{C_{e}}{Q_{0}}$

where $\mathrm{q}_{\mathrm{e}}$ is the mass of adsorbate adsorbed per unit mass of adsorbent, $\mathrm{C}_{\mathrm{e}}$ is the equilibrium concentration of the adsorbate, $\mathrm{b}$ and $\mathrm{Q}_{0}$ are the Langmuir constants which are dependent on the rate and adsorption capacity respectively. To confirm the acceptance of the process, the dimensionless equilibrium parameter $\mathrm{R}_{\mathrm{L}}$ was used (equation 4)(Kakavandi et al. 2014):

$R_{L}=\frac{1}{\left(1+b \times C_{o}\right)}$

Where, $\mathrm{b}$ is the Langmuir constant and $\mathrm{C}_{0}$ is the highest $\mathrm{MO}$ dye concentration $(\mathrm{mg} / \mathrm{L})$. $\mathrm{R}_{\mathrm{L}}$ values indicate the type of adsorption that is taking place (unfavorable $\left(R_{L}>1\right)$, favorable $\left(0<R_{L}<1\right)$, linear $\left(\mathrm{R}_{\mathrm{L}}=1\right)$ or irreversible $\left.\left(\mathrm{R}_{\mathrm{L}}=0\right)\right)$.

\subsubsection{Freundlich Isotherm}

Freundlich isotherm assumes varied scattering of the surface energy of the active sites which also depends on the surface coverage. The linear form of the Freundlich model is shown in equation 5(Kakavandi et al. 2014):

$\log q_{e}=\log K_{F}+1 / n \times \log C_{e}$ 
where $\mathrm{K}_{\mathrm{F}}$ and $\mathrm{n}$ are constants combining the factors affecting the adsorption capacity and the amount of non-linearity between the MO dye concentration in the solution and the amount adsorbed at equilibrium, respectively. The value of $1 / \mathrm{n}$ summarizes the adsorption characteristics. If the value is between 0 and 1 , the adsorption intensity attains a more nonuniform distribution. Moreover, if the value is less than 1, normal Langmuir isotherm can elucidate the adsorption process without loss of generalization while a value greater than 1 is a characteristic of co-operative adsorption (Zeinali et al. 2014, Kakavandi et al. 2014).

\subsubsection{Pseudo-First-Order kinetic model}

The Lagergren pseudo-first-order model has established on the postulation that the adsorption rate is related to the number of existing adsorption sites, and is expressed in equation 6 (Karimi et al. 2014, Azari et al. 2015):

$\frac{d q_{t}}{d t}=K_{1}\left(q_{e}-q_{t}\right)$

Where, $\mathrm{K}_{1}(1 / \mathrm{min})$ is the rate constant of the pseudo-first-order adsorption, $\mathrm{q}_{\mathrm{t}}$ and $\mathrm{q}_{\mathrm{e}}(\mathrm{mg} / \mathrm{g})$ are the amounts of the adsorbate adsorbed per gram of adsorbent at any time $t$ and at equilibrium, respectively. Applying $\mathrm{t}=0$ to $\mathrm{t}=\mathrm{t}$ and $\mathrm{q}_{\mathrm{t}}=0$ to $\mathrm{q}_{\mathrm{t}}=\mathrm{q}_{\mathrm{t}}$ as the boundary conditions, and integrating, the following equation 7 is obtained (Zeinali et al. 2014):

$\ln \left(q_{e}-q_{t}\right)=\ln q_{e}-K_{1} t$

The plot of $\ln \left(\mathrm{q}_{\mathrm{e}}-\mathrm{q}_{\mathrm{t}}\right)$ against $\mathrm{t}$ permits the kinetic model to be assessed and the values of $\mathrm{K}_{1}$ and $\mathrm{q}_{\mathrm{e}}$ to be determined from the slope and intercept, respectively.

\subsubsection{Pseudo-Second-Order kinetic model}

The pseudo-second-order kinetic model was founded on the hypothesis that the adsorption rate is proportionate to the square of the number of vacant adsorption sites. It is shown inequation 8 (Zeinali et al. 2014): 
$\frac{d q_{t}}{d t}=K_{2}\left(q_{e}-q_{t}\right)^{2}$

Where $\mathrm{K}_{2}(\mathrm{~g} / \mathrm{mg} \mathrm{min})$ is the rate constant of the pseudo-second-order adsorption. Applying $\mathrm{t}=0$ to $\mathrm{t}=\mathrm{t}$ and $\mathrm{q}_{\mathrm{t}}=0$ to $\mathrm{q}_{\mathrm{t}}=\mathrm{q}_{\mathrm{t}}$ as the boundary conditions, and integrating, the following equation 9 is obtained (Zeinali et al. 2014):

$\frac{1}{\left(q_{e}-q_{t}\right)}=\frac{1}{q_{e}}+K_{2} t$

Equation 9 is generally expressed as equation 10 (Karimi et al. 2014):

$\frac{t}{q_{t}}=\frac{1}{K_{2} q_{e}^{2}}+\frac{t}{q_{e}}$

Where $\mathrm{K}_{2} \mathrm{q}_{\mathrm{e}}{ }^{2}$ can be considered as the preliminary adsorption rate as $\mathrm{t} \rightarrow 0$. The plot of $\mathrm{t} / \mathrm{q}_{\mathrm{t}}$ against $\mathrm{t}$ permits the kinetic model to be assessed and the values of $\mathrm{K}_{2}$ and $\mathrm{q}_{\mathrm{e}}$ to be determined from the intercept and slope, respectively.

\subsection{Development of a Genetic Algorithm}

\subsubsection{Artificial Neural Network (ANN)}

ANNs are highly efficient, non-linear analytical tools that can find the relationship between input/output data without previous information of the connection among the variables involved in the scheme (Hoda et al. 2006). The essentials of a neural network are the neurons, which are concealed and output layers of the network (Figure 1).

$a_{i}=m \sum_{j=1}^{m} W_{i j} X_{j}$

$n_{i}=f\left(a_{i}+b_{i}\right)$

in which are the input values, $\mathrm{w}_{\mathrm{ij}} \mathrm{s}$; are the weights of neuron $\mathrm{i}, \mathrm{b}_{\mathrm{i}}$ is the bias, $\mathrm{f}(-)$ is the initiation function, and $n_{i}$ is the yield value of the neuron. 


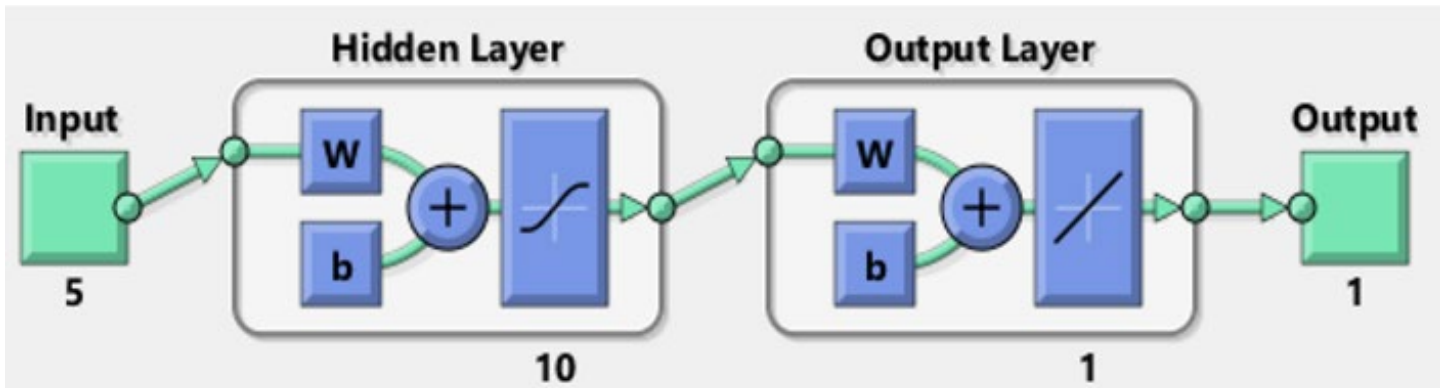

Figure 1: Schematic representation of the Artificial Neural Network

The ANN method resolves problems using a multilayer perceptron (MLP). This MLP topology is made of (i) input layer of the neuron (independent variables), (ii) a number of hidden layers, and (iii) output layer (dependent variables) (Kumar et al. 2009). The complexity of the problem decides the number of hidden layer neurons. Most problems can be modeled by ten hidden layers. An algorithm known as "training" is used by the MLP to learn the data pattern and modify weights of the neurons in accordance with the error between the values of real and net output that gives the connection between inputs and outputs variables and are very valuable in identifying forms in intricate statistics (Mitra et al. 2018). An instance of training algorithms is the backpropagation algorithm that is extensively used to train ANN in numerous complications of science and engineering.

\subsubsection{Optimal conditions based on genetic algorithm}

A successful method for solving linear and nonlinear problems is the genetic algorithm (GA). The algorithm discovers diverse parts of the constricted space and guides the pursuit to the area wherever a high prospect of global optimum occurs (Ahn 2006 and Montgomery 2007). In the planned technique, the ANN is trained and subsequently, the genetic algorithm then can be used to improve the input variables, with a goal to maximize the percentage of dye removal. GA based optimization methods were performed by utilizing trained ANN models as the suitability functions to yield the globally optimized solutions (Zhang et al. 2010, Carlos et al. 2010). A neural network with three layers $(\mathrm{M}-3)$; the $l$ th layer has $n l$ neurons. Given $\mathrm{S}$ training samples $\left(\mathrm{U}_{\mathrm{s}}, \mathrm{T}_{\mathrm{s}}\right), \mathrm{s}=1,2,3 \ldots \mathrm{S}$, where $U_{s}=\left[u_{1}^{S}, \ldots, u_{n_{l}}^{s}\right]$ and $T_{s}=\left[t_{1}^{S}, \ldots ., t_{n_{M}}^{S}\right]$. For certain input $U=$ $\left[u_{l}, \ldots, u_{n_{l}}^{s}\right]$ of the network, the input $x_{1}^{l}$ and output $y_{1}^{l}$ of $i^{\text {th }}$ neuron of $1^{\text {th }}$ layer are as follows (Carlos et al. 2010): 
Input Layer

$y_{0}^{l}=x_{0}^{l} \equiv 1$,

$y_{j}^{l}=x_{j}^{l} \equiv u_{j}$,

Where $\mathrm{j}=1,2 \ldots n_{l}$

Hidden Layer

$y_{0}^{l}=x_{0}^{l} \equiv 1$,

$x_{j}^{1}=\sum_{i=0}^{n_{l-1}} w_{i, j}^{l-1, l} y_{i, j}^{l-1}$,

$y_{j}^{l}=g\left(x_{j}^{l}\right)=\frac{1}{\left(1+\exp \left(-x_{j}^{l}\right)\right)}$

Where $\mathrm{j}=1,2 \ldots n_{l} l=1,2 \ldots \mathrm{M}-1 . w_{i, j}^{l-1, l}$ is the weight from the $i^{\text {th }}$ neuron of $(l-1)^{\text {th }}$ layer to the $j^{\text {th }}$ neuron of $l^{\text {th }}$ layer, and $\mathrm{g}($.$) is the transfer function.$

Output Layer

$x_{j}^{M}=\sum_{i=0}^{n_{M-1}} w_{i, j}^{M-1, M} y_{i, j}^{M-1}$,

$y_{j}^{M}=g\left(x_{j}^{M}\right)=\frac{1}{\left(1+\exp \left(-x_{j}^{M}\right)\right)}$

Where $\mathrm{j}=1,2 \ldots n_{M}$, Training a neural network minimizes the error function by modifying the weights $w_{i, j}^{l-1}$. The widely used training error function is as follows:

$E=\sum_{S=1}^{S} E_{S}=\frac{1}{2} \sum_{S=1}^{S} \sum_{i=1}^{N_{M}}\left(t_{i}^{S}-y_{i}^{S, M}\right)$

Where, $y_{i}^{S, M}$ is the output of $i^{\text {th }}$ neuron of $\mathrm{M}^{\text {th }}$ layer when inputting $\mathrm{s}^{\text {th }}$ sample.

The GA was trained in stages as follows: (1) The preliminary population was selected arbitrarily. Each individual of the initial generation was categorized by a random set of ANN weights; (2) every individual of the population was assessed: for doing this the ANN was run for all $\mathrm{S}$ experimental inputs, to compute the yields, utilizing the weights related to each discrete 
individual. Afterward, the computed outputs were related to the experimental ones; (3) the individuals of the population were graded according to the lower "E" (neural network error values Eq. (7)); (4) The lowest "E" value of the population (best individual) was copied to the next generation (elitism); (5) The finest parents were elected to produce the progenies, using the GA operators; (6) Similar method is repeated for the next generation and the algorithm is run for a definite number of cycles (Soleymani et al. 2011). The ultimate set of weights (chromosome of the best individual the previous generation) is kept for backpropagation (BP) training; (7) after concluding the GA training, the BP algorithm begins from the solution given by GA. The BP continues in accordance with the conjugate gradient backpropagation training method, reducing the error "E" until it lies below a particular limit determined by the user (Karimi et al. 2011). As the training is completed, the ANN is used to estimate the density values for a new set of data (Testing and unseen data). The overall BPN-GA training algorithm is represented in Figure 2. 


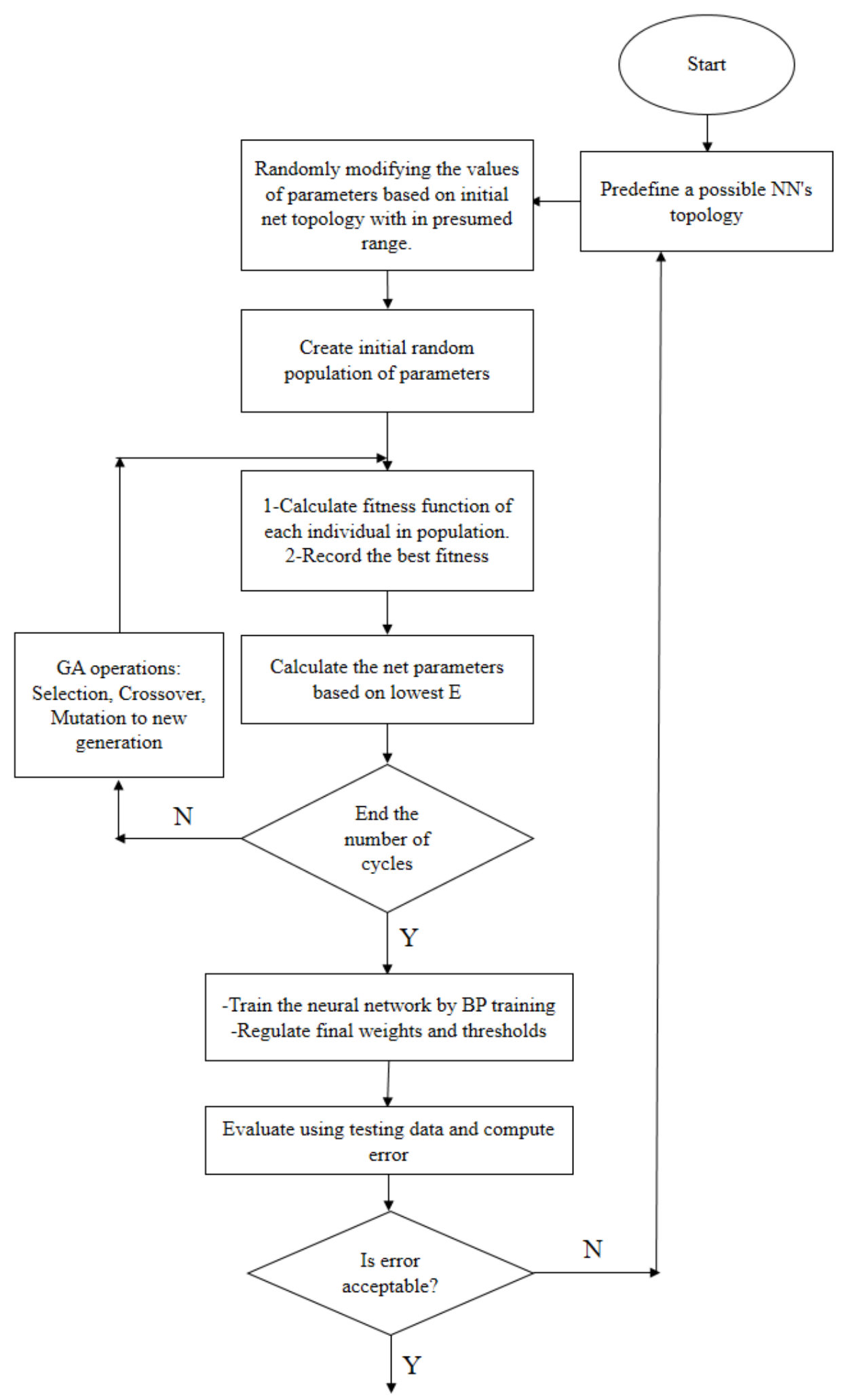

Figure 2: Flow chart representing the BPN-GA training algorithm 


\subsubsection{Design of Experiments}

In this study, ANN was established utilizing five parameters to find out the removal efficiency of the MO solution by using DSAC/Fe. It is imperative to assure that the data set covers a substantial range of the variables to have good ANN training. Else, the model could fail on the generalization test and could be limited to the fine range of the parameters characterized by the experimental data. One of the dangers of ANN training is the over-training when the net fits effortlessly to the data used for training, but it is rendered ineffective to deal with new data. Initially, the ANN training was started with 2 neurons in the hidden layer and progressively the neurons number increased. The performance of the network in the training phase should increase as the number of neurons increases, while the performance of the network in the testing data stage leads to an optimum value at an optimal number of hidden neurons. In all instances, the trained ANN was used to calculate the removal efficiency of MO dye at varied situations not used for training (testing data) and the results were compared to experimental ones. $\mathrm{pH}$, adsorbent dosage, initial dye concentration, time and temperature are the input nodes of the ANN model while removal efficiency of $\mathrm{MO}$ dye is the output node. These are the significant parameters that influence the adsorption quality of DSAC/Fe. 50 experiments were performed as test runs to train the ANN model. Table 1 lists the parameter range within which different experiments were carried out.

Table 1: The parameter range within which different experiments were carried out

\begin{tabular}{|l|l|}
\hline Parameter & Range \\
\hline $\mathrm{pH}$ & $2-12$ \\
\hline Adsorbent dosage & $0.1-0.5 \mathrm{~g} / \mathrm{L}$ \\
\hline Initial dye concentration & $1-10 \mathrm{mg} / \mathrm{L}$ \\
\hline Time & $5-300 \mathrm{~min}$ \\
\hline Temperature & $30-70{ }^{\circ} \mathrm{C}$ \\
\hline
\end{tabular}




\section{Results and Discussion}

\subsection{Chemical and morphological characterization of DSAC/Fe}

Fig. 3 illustrates the morphological characteristics of DSAC/Fe material acquired from SEM. Figures 3A and 3B illustrate the $\mathrm{DSAC} / \mathrm{Fe}$ structure at $100 \mu \mathrm{m}$ magnification. It can be clearly seen that the deposition of the iron particles had altered the surface characteristics of the activated carbon. The prominence of pores can be considered distinct surrounding which the iron at different states of oxidation can be seen to exist. It can also be observed that the pores attained are micropores (Karimi et al. 2012). The white particles present on the surface of this porous carbon were the complexes of iron (Fig. 3B). Iron particles are not only present on the surface of carbon, but some iron had penetrated the pores of carbon thereby causing a reduction in the porosity by forming $\mathrm{Fe}_{2} \mathrm{O}_{3}, \mathrm{Fe}_{3} \mathrm{O}_{4}$, etc. (Alslaibi et al. 2013).

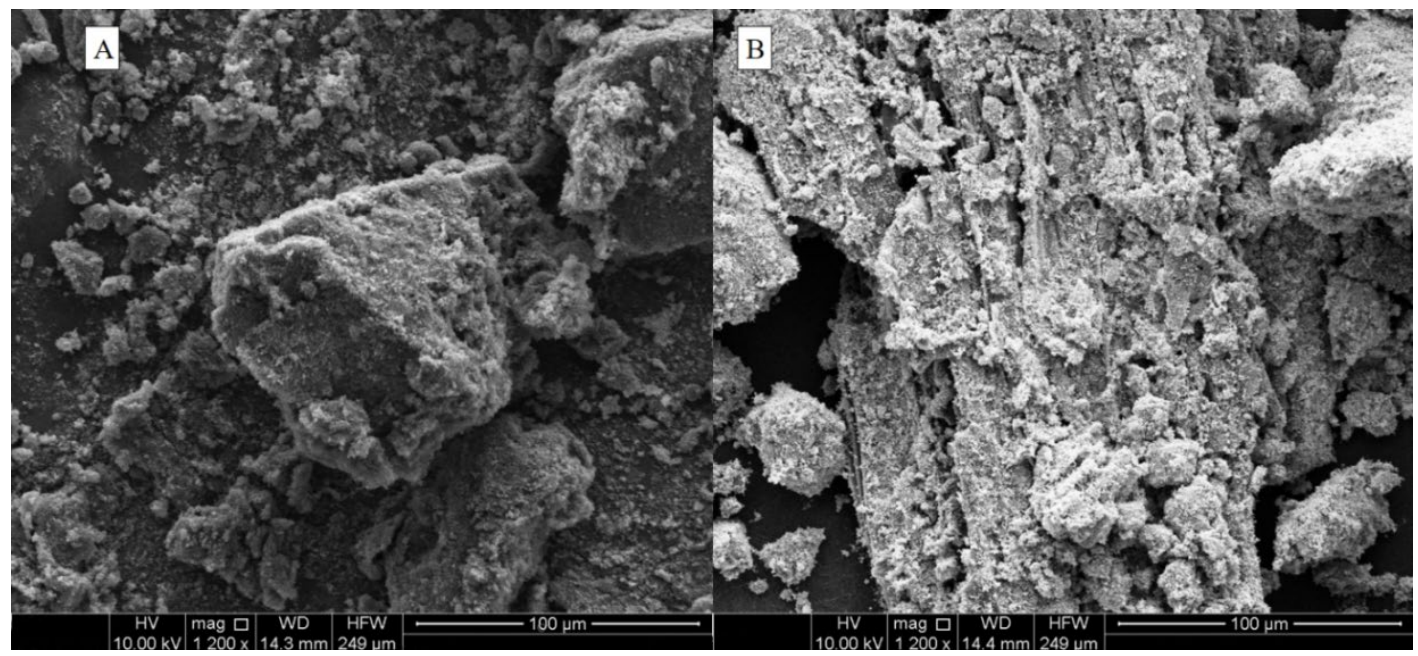

Figure 3: SEM images of (A) Activated Carbon (DSAC) (B) DSAC/Fe

Fig. 4A shows the XRD profile of the activated carbon produced from Date stones. The prepared activated carbon exhibits a very broad band of diffraction peaks along with the absence of sharp peaks which indicated that it is predominantly an amorphous structure (Sivapathasekaran et al. 2010). There are two broad diffraction peaks around $2 \theta=24.6^{\circ}$ and $43.1^{\circ}$ in the spectrum, corresponding to the diffraction of $\left(\begin{array}{lll}0 & 0 & 2\end{array}\right)$ and $\left(\begin{array}{lll}1 & 0 & 0\end{array}\right)$, respectively. 

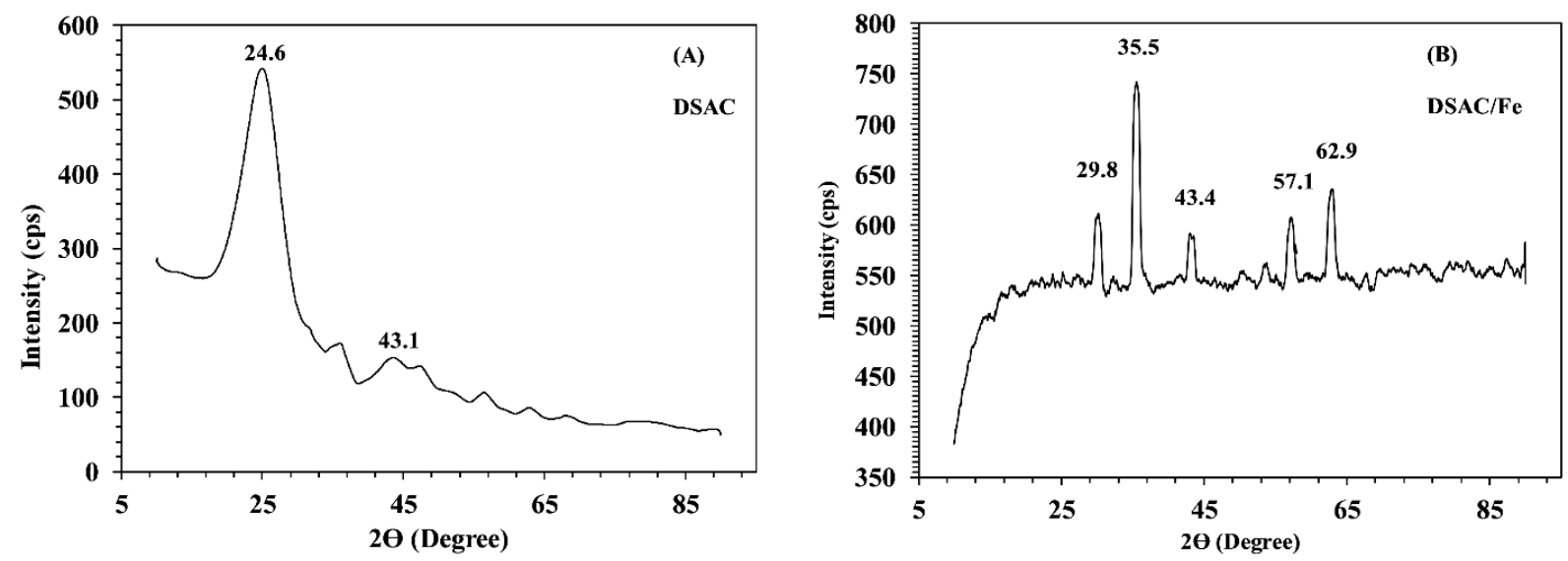

Figure 4: XRD image of (A) Activated Carbon (DSAC) (B) DSAC/Fe showing the peaks of Fe

Fig. 4B shows the XRD patterns as obtained for DSAC/Fe. Two crystalline phases can be distinctly determined from the XRD pattern. The two characteristic crystalline phases are of magnetite and hematite. Magnetite is an oxidized crystal form of iron with an inverse spinel-type cubic structure having two active sites that are not equivalent in symmetry (Ghaedi et al. 2011). The two nonequivalent structures being tetrahedral and octahedral while hematite being a crystalline solid of the hexagonal compact structure. 29.8, 35.5, 43.4, 57.1 and 62.9 are the intensities obtained at $2 \theta$ values. Furthermore, a higher degree of crystallinity is observed at the magnetite portion of the material. It may be worth stating here about another member of the iron oxide family namely maghemite, containing the cubic structure of inverse spinel-type having a similar structure to that of magnetite only differing in the fact that exclusively contains Fe(III) oxide (Mesdaghinia et al. 2017, Azari et al. 2019). Similarly, in the structure of maghemite and magnetite makes it very difficult for the distinct identification of one form to the other using XRD alone as a characterization method (Qada et al. 2006).

The FTIR spectra for both DSAC and DSAC/Fe were recorded in the range of 4000-300 $\mathrm{cm}^{-1}$ and are depicted in Fig 5. In DSAC, the band $2938 \mathrm{~cm}^{-1}$ is attributed to asymmetric and symmetric aliphatic bonding $\mathrm{C}-\mathrm{H}$ stretching vibrations. The bands centered at 1682 and 1569 $\mathrm{cm}^{-1}$ can be assigned to the presence of $\mathrm{C}=$ Cstretching vibration of the aromatic rings. The band at $1433 \mathrm{~cm}^{-1}$ may be a result of the angular deformation of the $\mathrm{O}-\mathrm{H}$ bonds, or due to $\mathrm{C}-\mathrm{H}$ aliphatic and aromatic groups in the deformation vibrations of methyl and methylene groups. The bands between 1000 and $1300 \mathrm{~cm}^{-1}$ can be assigned to the $\mathrm{C}-\mathrm{O}$ stretching vibration of carboxylic acids and alcohols, and $\mathrm{C}-\mathrm{N}$ in aliphatic amines. Finally, the vibration bands below $900 \mathrm{~cm}^{-1}$ 
may be linked to the aromatic ring, $\mathrm{C}-\mathrm{H}$ bond with different degrees of substitution, or to N-H bonds according to the literature. The characteristic absorption peak appearing at $3484.8 \mathrm{~cm}^{-1}$ $\mathrm{DSAC} / \mathrm{Fe}$ spectra can be assigned to the moisture contents/chemisorbed water in the sample matrix or due to the $\mathrm{O}-\mathrm{H}$ stretching and bending vibrations as suggested by Liu et al. However, no such peak was found in the FTIR spectrum of DSAC. A small peak at $1596.89 \mathrm{~cm}^{-1}$ in DSAC but comparatively sharper peak at $1634.73 \mathrm{~cm}^{-1}$ in DSAC/Fe due to the stretching vibration of $\mathrm{C}=\mathrm{O}$ was detected.
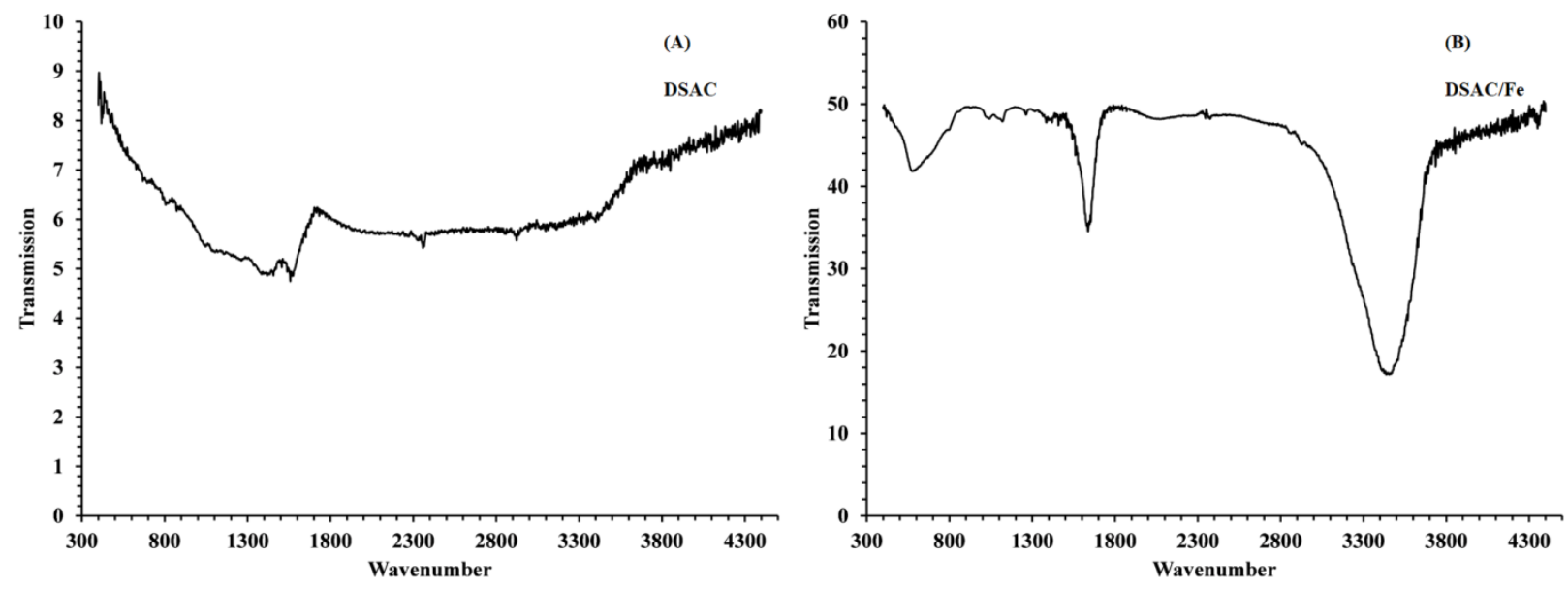

Figure 5: FTIR spectra of (A) Activated Carbon (DSAC) (B) DSAC/Fe

Both the specific surface area and pore volume values of DSAC/Fe decreases significantly on the incorporation of Fe and the specific surface area reaches 1031.467 to 738 $.6571 \mathrm{~m}^{2} / \mathrm{g}$, respectively, and the total pore volume decreases from 0.615901 to $0.27277 \mathrm{~cm}^{3} / \mathrm{g}$, respectively, for DSAC and DSAC/Fe. The physical properties of DSAC and DSAC/Fe including BET surface area $\left(\mathrm{S}_{\mathrm{BET}}\right)$, micropore surface area $\left(\mathrm{S}_{\text {mic }}\right)$, total pore volume $\left(\mathrm{V}_{\mathrm{T}}\right)$, micropore volume $\left(V_{\text {mic }}\right)$ and average pore diameter $\left(D_{p}\right)$ are given in Table 2 .

Table 2. Texture characteristics of DSAC and DSAC/Fe.

\begin{tabular}{|l|l|l|l|l|l|l|}
\hline \multirow{2}{*}{ Adsorbent } & \multicolumn{4}{|l|}{ Surface area of pores $\left(\mathbf{m}^{\mathbf{2}} / \mathbf{g}\right)$} & \multicolumn{3}{l|}{ Pore volume $\left(\mathrm{cm}^{\mathbf{3}} / \mathbf{g}\right)$} \\
\cline { 2 - 7 } & $\boldsymbol{S}_{\boldsymbol{B E T}}$ & $\boldsymbol{S}_{\text {ext }}$ & $\boldsymbol{S}_{\text {mic }}$ & $V_{\boldsymbol{T}}$ & $V_{\text {mes }}$ & $V_{\text {mic }}$ \\
\hline DSAC & 1031.467 & 686.7637 & 386.2458 & 0.615901 & 0.407139 & 0.19463 \\
\hline
\end{tabular}




\begin{tabular}{|l|l|l|l|l|l|l|}
\hline DSAC/Fe & 738.6571 & 293.41026 & 94.0253 & 0.27277 & 0.10965 & 0.05707 \\
\hline
\end{tabular}

\subsection{Training of ANN}

A three-layer MLP with a tangent sigmoid transfer function at the hidden layer and a linear transfer function at the output layer were used in this work. The developed ANN model had three layers as illustrated in Fig. 2. The experimental removal efficiency and the efficiency predicted by the ANN model are illustrated in Fig. 6. In total, 50 different sets of experiments were carried out to train the model. The maximum standard deviation obtained between the experimental value and the predicted value was 6.64 while the least deviation was 0.07 . Similar results were reported using activated carbon from pine seeds, waste tire and spent tea leaves (Ghaedi et al. 2017, Ozbelge et al. 2002, Roosta et al. 2014).

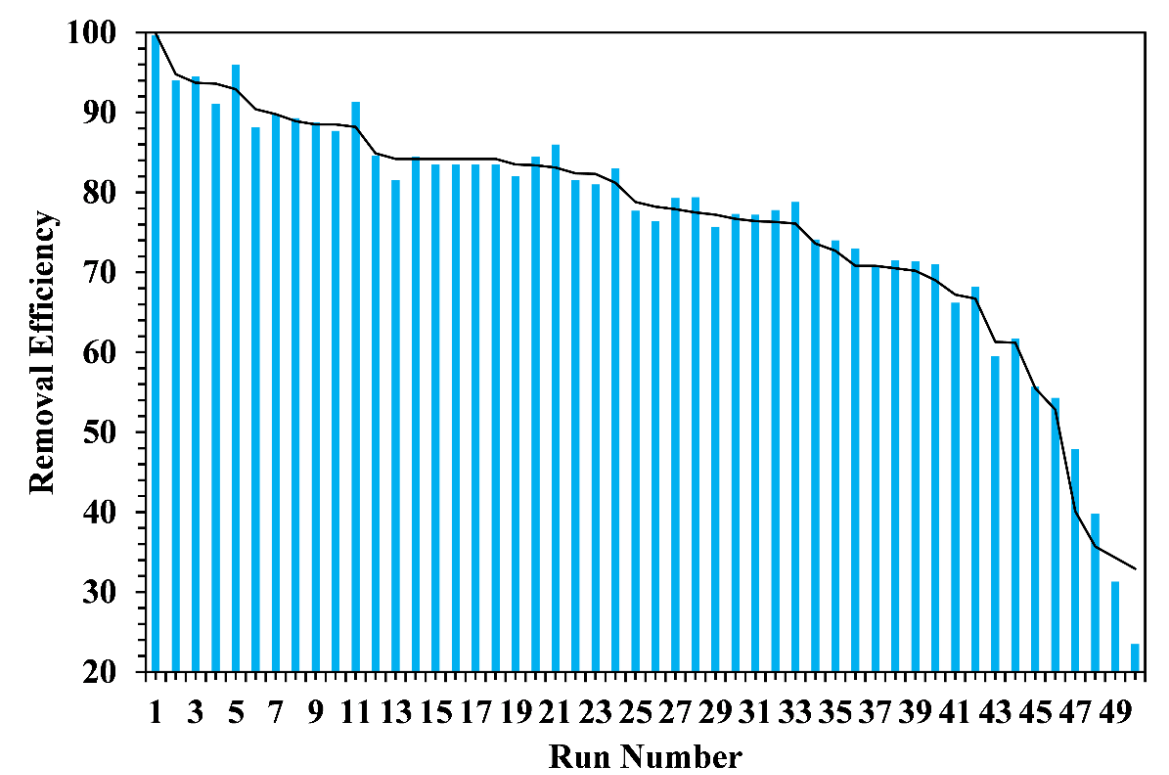

- Removal Efficiency -Removal Efficiency predicted by ANN

Figure 6: Removal efficiency of MO dye for each of the 50 different experiments

From Fig. 6 it can be observed that the removal efficiency varied for each of the 50 experiments as the parameter's values were different for each of the runs. The ANN model formed in this study, containing three layers and ten neurons were analyzed at a learning rate of 0.01 and 700 epochs to obtain a dynamic model for the adsorption of MO solution using $\mathrm{DSAC} / \mathrm{Fe}$. The regression coefficient was selected for assessing the performance standard of the 
model. To avoid net complexity and overtraining probability, the ten neurons were chosen for the hidden layer. The configuration of the trained neural network was accomplished in terms of weights and bias values of each layer after the training and validation of construct networks (Roosta et al. 2014). At epoch 13 the best validation performance was obtained (Fig. 7).

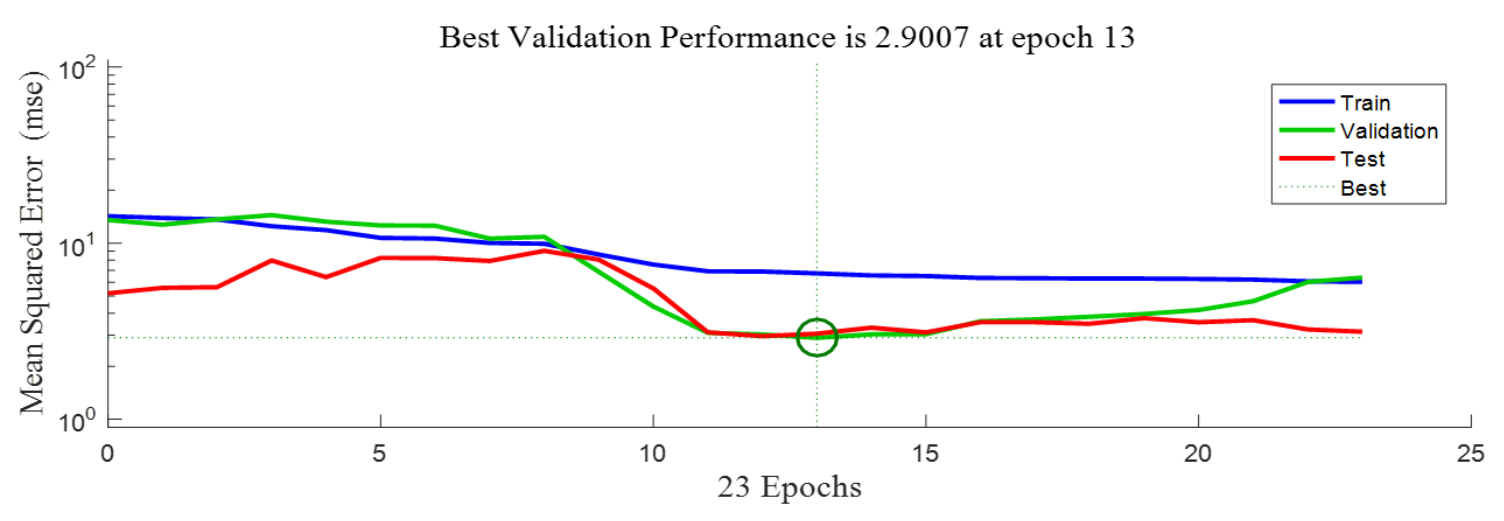

Figure 7: Validation performance of the ANN

The results of the testing data are calculated and presented in Fig. 8. The regression coefficient of both training and validating was stopped when it was greater than 0.95 . This program was performed using MATLAB. From Fig. 7 we can see that the $\mathrm{R}^{2}$ value for training was 0.98 and validation was 0.99 . These results confirm that the ANN model could simulate the adsorption process adequately well, under different conditions, within the experimental range adopted in the model fitting. 

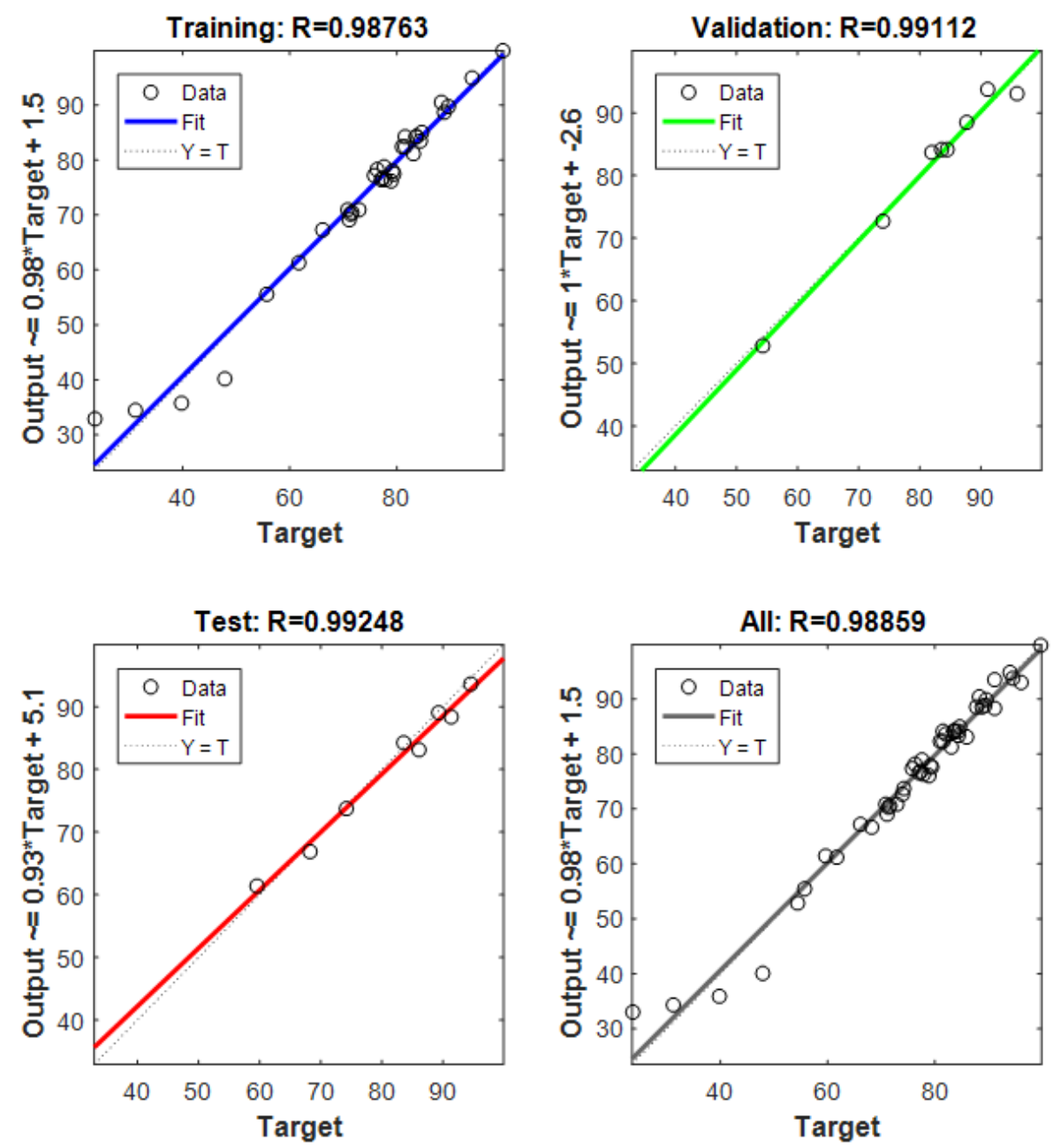

Figure 8: $\mathrm{R}^{2}$ value of training and validation

\subsection{Effect of different parameters on the removal efficiency of MO dye}

\subsubsection{Effect of $\mathrm{pH}$ on the removal of MO dye}

The $\mathrm{pH}$ of an aqueous solution is a very significant parameter in the dye adsorption process as it affects the surface charge of the adsorbent material and the amount of ionization of the dye molecule. The effect of initial $\mathrm{pH}$ on $\mathrm{MO}$ adsorption onto DSAC/Fe is presented in Figure 8. The adsorbent dosage and initial dye concentration were kept constant at $0.5 \mathrm{~g} / \mathrm{L}$ and $10 \mathrm{mg} / \mathrm{L}$, respectively. The temperature and time for the process was fixed at $30{ }^{\circ} \mathrm{C}$ and 300 
minutes while the $\mathrm{pH}$ was varied between 2 and 11. As the figure illustrates, $\mathrm{pH}$ had a prominent effect on the removal of the dye from the aqueous solution. The removal efficiency was seen to be marginally increased in the $\mathrm{pH}$ range of 1-3. It was seen to attain a highest of $76.6 \%$ at $\mathrm{pH} 2$, while a conflicting removal efficiency of only $57.7 \%$ was noted at $\mathrm{pH} 11$. The ANN predicted model also showed the same trend as the experimental values (Fig 9). The maximum removal efficiency obtained by the model was $76.3 \%$ and the least was $58.2 \%$. The maximum standard deviation of 1.06 was obtained at $\mathrm{pH} 3$ while the least deviation of 0.07 was observed at $\mathrm{pH} 7$. At basic $\mathrm{pH}$ conditions, the double bond conjugation of $\mathrm{MO}$ dye was lost along with a proton, and the molecule rearranges to form a negatively charged species (Sivapathasekaran et al. 2010). The positive charges were neutralized. At high $\mathrm{pH}$, the surplus anions in the solution will repel the dye from the negatively charged surfaces of the adsorbents. Moreover, an increase in $\mathrm{pH}$ leads to the alteration of the pi (П) system delocalization pattern (Li et al. 2011). Additionally, at lower $\mathrm{pH}$, the surface of the DSAC/Fewas activated by the acid in the solution and the MO dye became protonated and thus enhanced the adsorption process.

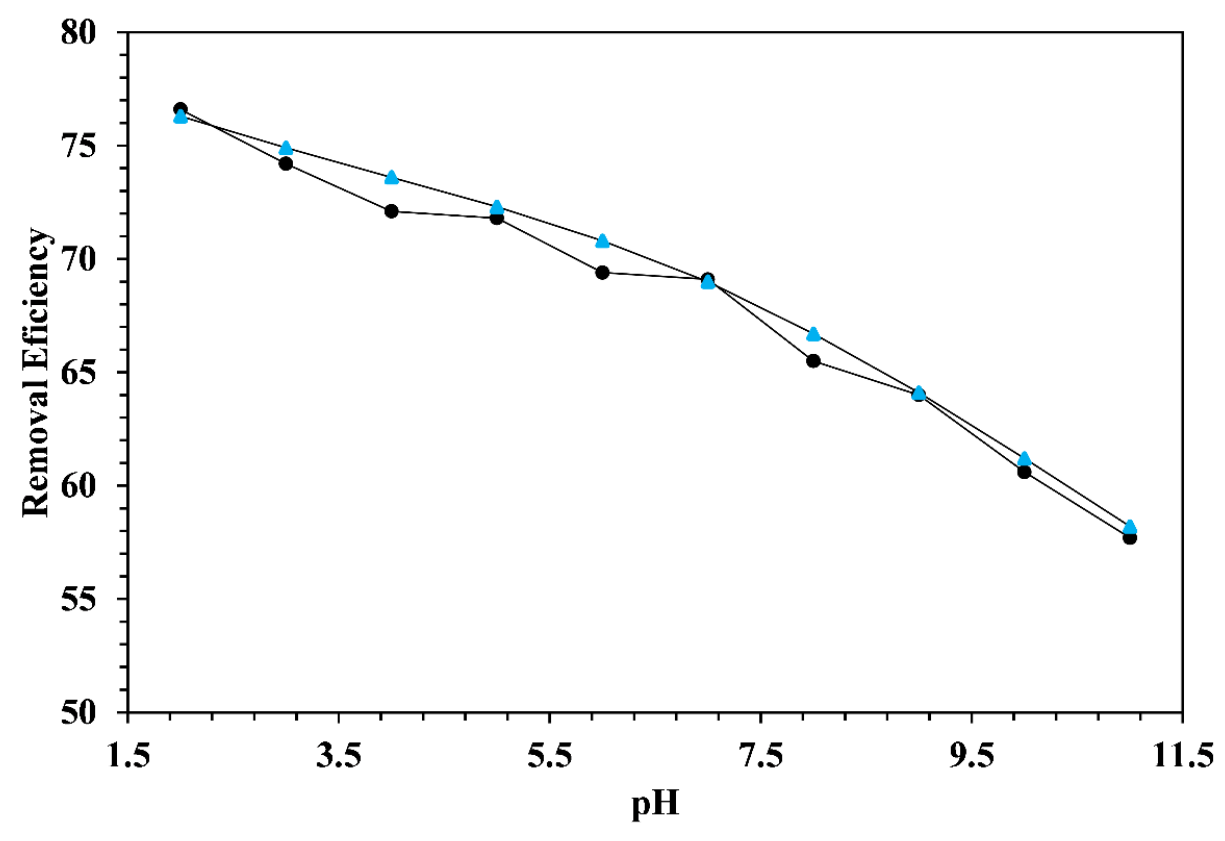

$\bullet-$ Removal Efficiency $\quad \rightarrow$ ANN predicted Removal Efficiency

Figure 9: Effect of $\mathrm{pH}$ on the removal efficiency of $\mathrm{MO}$ 


\subsubsection{Effect of initial dye concentration in the removal of MO dye}

An initial concentration of $\mathrm{MO}$ dye in the range of $2-20 \mathrm{mg} / \mathrm{L}$ was taken where absorption onto $\mathrm{DSAC} / \mathrm{Fe}$ was carried out. The adsorbent dosage and $\mathrm{pH}$ were kept constant at $0.5 \mathrm{~g} / \mathrm{L}$ and 2 , respectively. The temperature and time for the process was fixed at $30^{\circ} \mathrm{C}$ and 300 minutes. From Figure 9 it can be seen that the removal efficiency steadily decreased with the increase in the concentration of the MO dye. As expected, the ANN predicted model showed the same trend as that of the experimental values (Fig. 10). The maximum removal efficiency obtained by the model was $105.1 \%$ while the lowest removal efficiency was $69.3 \%$. The maximum standard deviation of 4.24 was obtained at $2 \mathrm{mg} / \mathrm{L}$ concentration. The corresponding value for $10 \mathrm{mg} / \mathrm{L}$ concentration was a meagre 0.21 . This increase in removal efficiency with the initial $\mathrm{MO}$ dye concentration onto $\mathrm{DSAC} / \mathrm{Fe}$ may be due to the fact that the escalation in the driving force to overcome the resistance of the mass transfer of MO dye between the solid phase and the aqueous phase, improving the interaction between MO and DSAC/Fe ( $\mathrm{Li}$ et al. 2011, Mukherjee et al. 2018). The decrease in the MO removal efficiency can be credited to the saturation of existing active sites on the absorbent above a certain concentration of adsorbate.

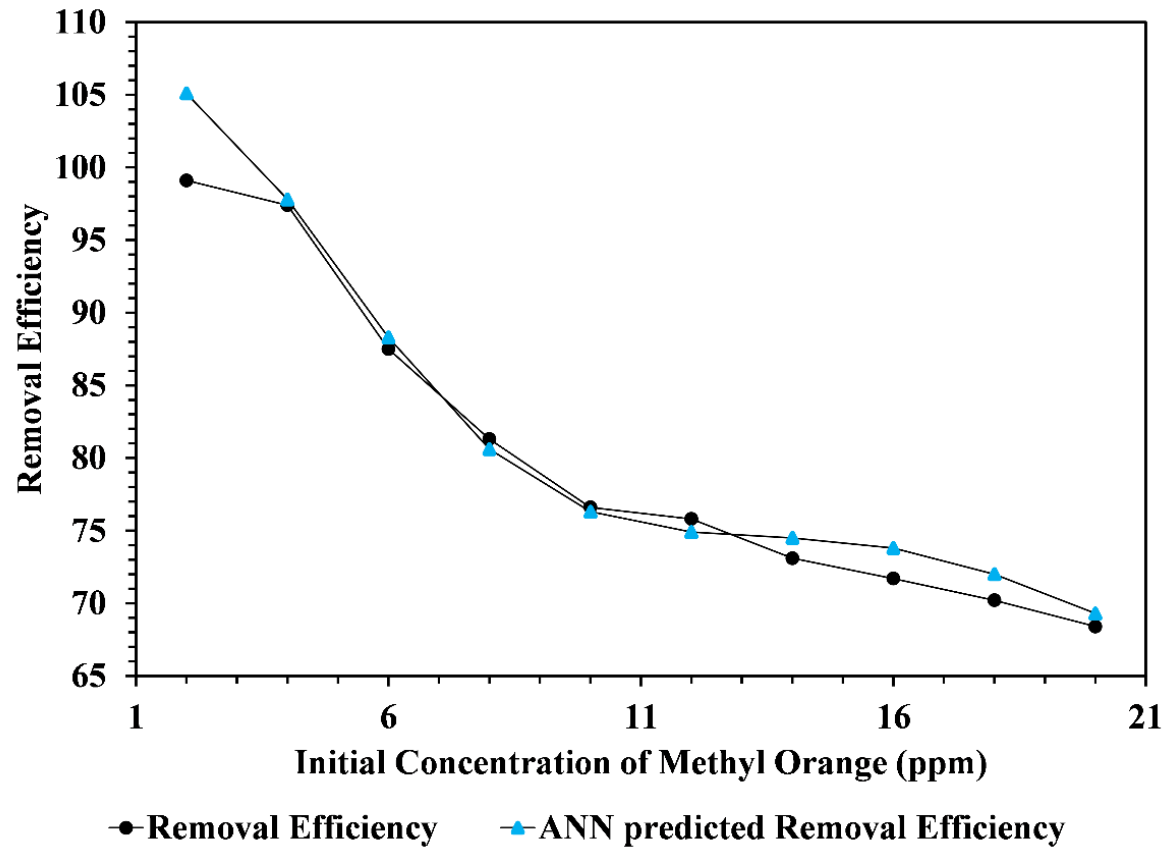

Figure 10: Effect of initial concentration on the removal efficiency of MO 


\subsubsection{Effect of adsorbent dosage in the removal of MO dye}

The amount of adsorbent used is a vital feature as it governs the degree of dye removal and can be used to regulate the cost of adsorbent per unit volume of solution to be treated. The adsorbent dosage of DSAC/Fevaried from $0.1-1.0 \mathrm{~g} / \mathrm{L}$. From Figure 11. a steady increase in the removal of $\mathrm{MO}$ with an increase in the amount of adsorbent dosage was noticed. The initial dye concentration and $\mathrm{pH}$ were kept constant at $10 \mathrm{mg} / \mathrm{L}$ and 2, respectively. Similarly, temperature and time for the process were also fixed at $30{ }^{\circ} \mathrm{C}$ and 300 minutes, respectively whilst the adsorbent dosage was varied from 0.1 to $1.0 \mathrm{~g} / \mathrm{L}$. The ANN predicted model showed the same trend as that of the experimental values. The maximum and minimum removal efficiency obtained by the experiment was $105.1 \%$ and $69.3 \%$, respectively. The maximum and minimum standard deviations of the model were 10.7 and 0.14 and were obtained at a dosage of 1.0 and $0.20 \mathrm{~g} / \mathrm{L}$, respectively. The probable reason for the increase in the number of free pores and surface area with an increase in dosage was greatly due to increasing in the adsorption and thus resulted in increased removal efficiency (Soleimani et al. 2012). The abrupt increase in removal efficiency when DSAC/Fedosage increased from 0.5 to $1.0 \mathrm{~g} / \mathrm{L}$ was probably due to the fact that the concentration difference or the split in the flux between the dye concentration in the aqueous solution and the dye concentration on the surface of the adsorbent (Gupta et al. 1997, Mitra and Mukherjee 2018).

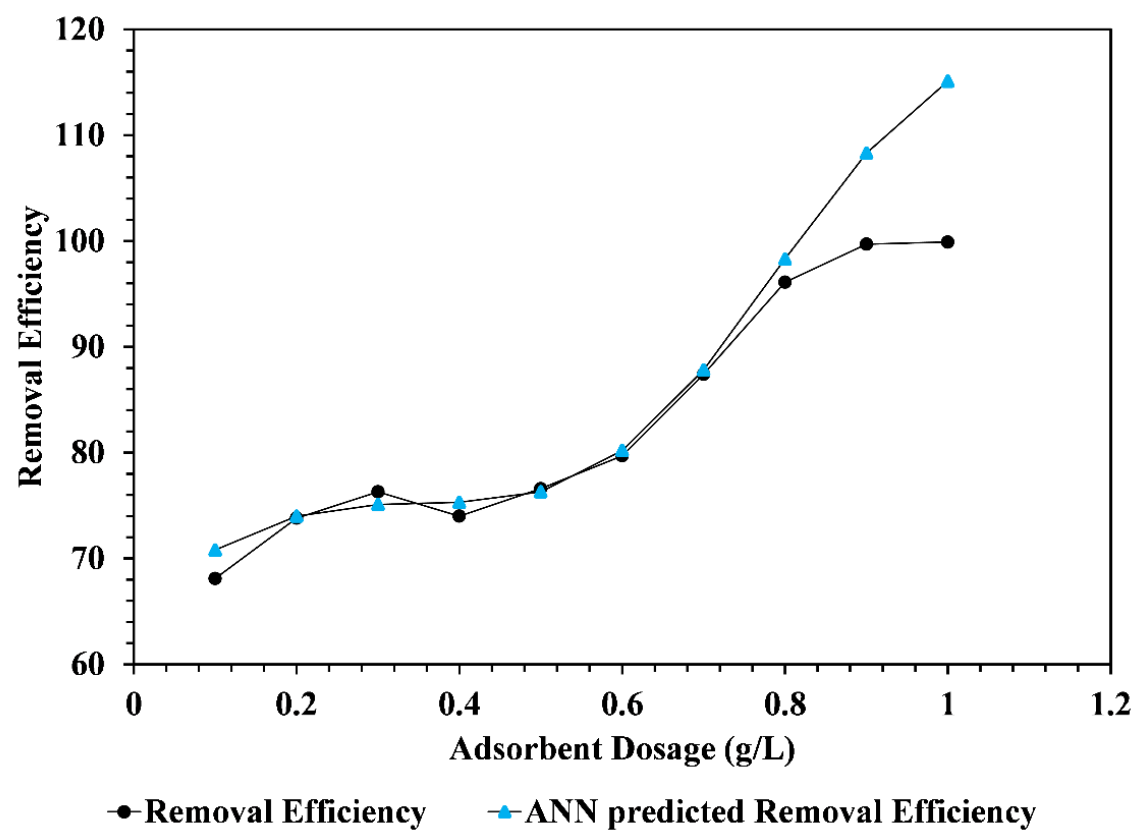

Figure 11: Effect of adsorbent dosage on the removal efficiency of MO 


\subsubsection{Effect of temperature in the removal of MO dye}

It is a well-established fact that temperature is another important parameter that critically affects any adsorption process. Fig. 12 shows the effects of different temperatures on the MO removal efficiency. The initial dye concentration and $\mathrm{pH}$ were kept constant at $10 \mathrm{mg} / \mathrm{L}$ and 2 , respectively. The adsorbent dosage and time for the process were fixed at $0.5 \mathrm{~g} / \mathrm{L}$ and 300 minutes while the temperature range varied from $30{ }^{\circ} \mathrm{C}$ to $75^{\circ} \mathrm{C}$. An increase in temperature from $30{ }^{\circ} \mathrm{C}$ to $65^{\circ} \mathrm{C}$ led to an increase in the removal efficiency of $\mathrm{MO}$ dye onto DSAC/Fe. This may be due to the fact that both an escalation in the MO dye motion to infiltrate inside the adsorbent pores, for the reduction in solution viscosity, and an increase in the interactions between the functional groups of the DSAC/Fe and the MOdye (Choy et al. 2004). From the figure, it can also be depicted that the adsorption of $\mathrm{MO}$ dye onto $\mathrm{DSAC} / \mathrm{Fe}$ is an endothermic process. However, form $65^{\circ} \mathrm{C}$ to $75^{\circ} \mathrm{C}$, the removal efficiency decreases. This is probably due to a more increase in the random motion of the pollutants, which leads to the desorption of the MO dye from DSAC/Fe.

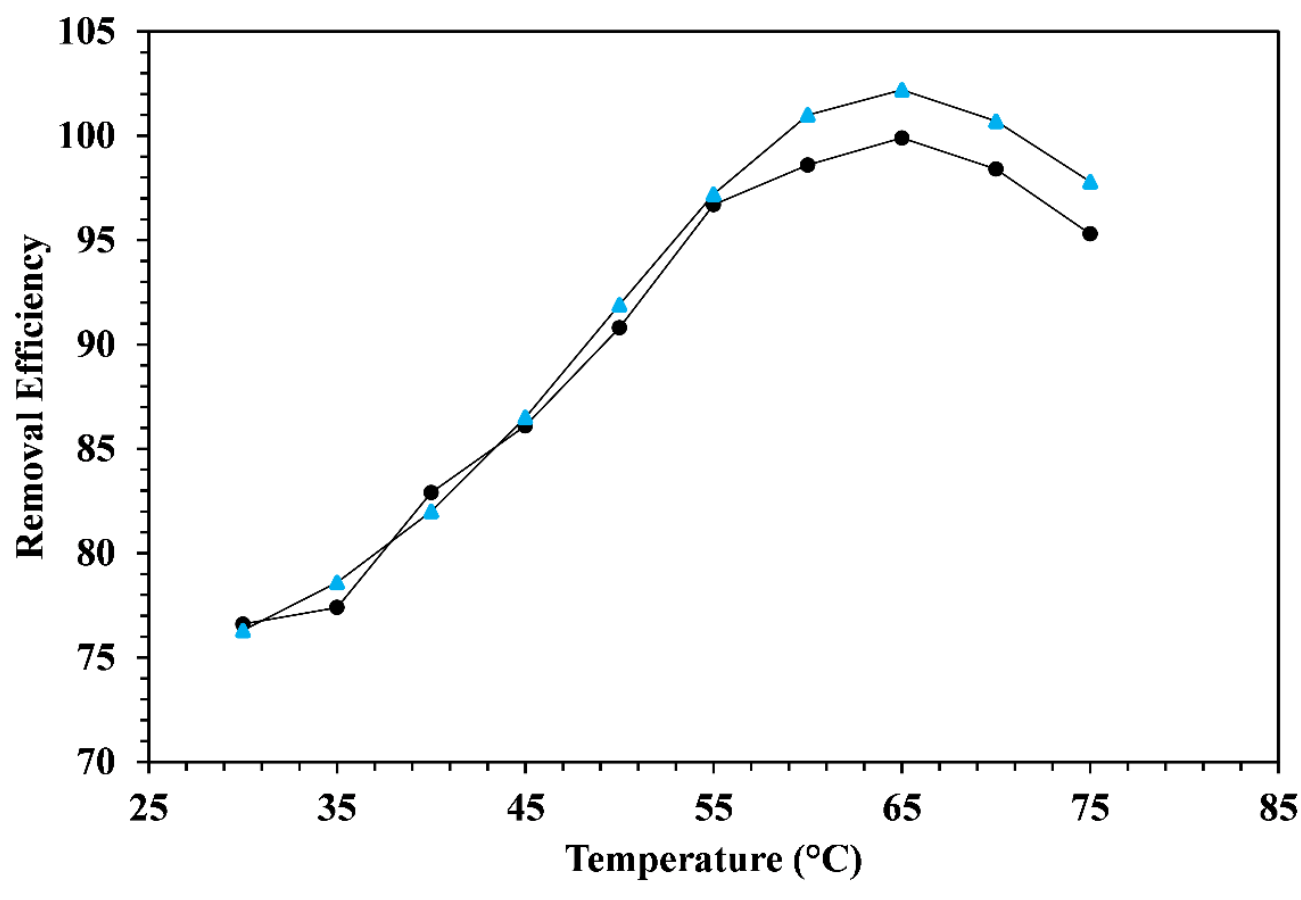

$\bullet-$ Removal Efficiency $\quad-$ ANN predicted Removal Efficiency

Figure 12: Effect of temperature on the removal efficiency of MO 
The thermodynamic parameters that are assessed are the changes in standard enthalpy $\left(\Delta \mathrm{H}^{\circ}\right)$, standard entropy $\left(\Delta \mathrm{S}^{\circ}\right)$ and standard free energy $\left(\Delta \mathrm{G}^{\circ}\right)$. The $\Delta \mathrm{H}^{\circ}$ and $\Delta \mathrm{S}^{\circ}$ are determined from Van't Hoff equation $(17,18)$ :

$\ln K=\frac{\Delta S^{\circ}}{R}-\frac{\Delta H^{\circ}}{R T}$

$\Delta G^{\circ}=-R T \ln K$

Where $\mathrm{R}$ is the universal gas constant $(8.314 \mathrm{~J} / \mathrm{mol} \mathrm{K}), \mathrm{T}$ is the absolute temperature and $\mathrm{K}$ is the equilibrium constant. The calculated values of $\Delta \mathrm{G}^{\circ}$ are given in Table 2. A negative worth of $\Delta \mathrm{G}^{\circ}$ suggests the viability and spontaneous nature of the surface assimilation method with a high preference of $\mathrm{MO}$ onto the $\mathrm{DSAC} / \mathrm{Fe}$. A positive worth of $\Delta \mathrm{H}^{\circ}$ indicates the energy-absorbing nature of the surface assimilation method and the process is endothermic in nature. The low values of each $\Delta \mathrm{G}^{\circ}(-200$ to $0 \mathrm{~kJ} / \mathrm{mol})$ and $\Delta \mathrm{H}^{\circ}$ correspond to physical surface assimilation (Kalantary et al. 2016). A positive worth of $\Delta \mathrm{S}^{\circ}$ reflects the inflated randomness at the solidaqueous interface with some structural changes in adsorbate and adsorbent. From Table 2, it can be observed that the $\Delta \mathrm{G}^{\circ}$ value increases at higher temperatures.

Table 2: $\Delta \mathrm{G}^{\circ}$ obtained by experiments and ANN model predicted

\begin{tabular}{|c|c|c|c|c|c|c|}
\hline $\begin{array}{l}\text { Temp. } \\
\text { (K) }\end{array}$ & $\begin{array}{l}\text { Experimental } \\
\Delta \mathbf{G}^{\circ}(\mathrm{KJ} / \mathrm{mol})\end{array}$ & $\begin{array}{l}\text { Experimental } \\
\Delta \mathbf{H}^{\circ}(\mathrm{KJ} / \mathrm{mol})\end{array}$ & $\begin{array}{l}\text { Experimental } \\
\Delta \mathbf{S}^{\circ}(\mathrm{J} / \mathrm{molK})\end{array}$ & $\begin{array}{l}\text { Model } \\
\text { Predicted } \\
\Delta G^{\circ} \\
(\mathrm{KJ} / \mathrm{mol})\end{array}$ & $\begin{array}{l}\text { Model } \\
\text { Predicted } \\
\Delta \mathbf{H}^{\circ} \\
(\mathrm{KJ} / \mathrm{mol})\end{array}$ & $\begin{array}{l}\text { Model } \\
\text { Predicted } \\
\Delta \mathbf{S}^{\circ} \\
(\mathrm{J} / \mathrm{molK})\end{array}$ \\
\hline 303 & -2987.35 & 7.557 & 0.0083 & -2945.38 & 7.548 & 0.0081 \\
\hline 308 & -3152.33 & & & -3331.44 & & \\
\hline 313 & -4107.85 & & & -3945.96 & & \\
\hline 318 & -4821.38 & & & -4910.84 & & \\
\hline 323 & -6148.15 & & & -6522.45 & & \\
\hline 328 & -9210.94 & & & -9673.05 & & \\
\hline
\end{tabular}




\subsubsection{Effect of time in the removal of MO dye}

A 55-minute time range was considered to study the removal efficiency of the MO solution onto DSAC/Fe. The initial dye concentration and $\mathrm{pH}$ were kept constant at $10 \mathrm{mg} / \mathrm{L}$ and 2 , respectively. The temperature and dosage for the process were fixed at $30{ }^{\circ} \mathrm{C}$ and $0.5 \mathrm{~g} / \mathrm{L}$, respectively while the time varied from 10 to 55 minutes with a 5-minute interval. From Figure 12, it was evident that there was a continuous increase in the removal efficiency with time. Removal efficiency by experiment was seen to attain a highest of $47.7 \%$ at a time of 55 minutes. On the contrary, only $34.2 \%$ removal efficiency noticed at a time of 10 minutes. The change in the rate of adsorption might be due to the fact that initially, all the adsorbent sites were vacant, and a solute concentration gradient was very high. Later, the lower adsorption rate was due to a decrease in the number of vacant sites of adsorbent and dye concentrations. The decreased absorption rate, particularly, toward the end of experiments, indicates the possible monolayer formation of MO on the adsorbent surface. This may be attributed to the lack of available active sites required for further uptake after attaining the equilibrium (Bellifa et al. 2017, Bakouri et al. 2009). From Fig. 13 it was observed that the ANN predicted model had a similar trend as that of the experimental values. The maximum removal efficiency obtained by the model was $47.5 \%$ and the least was $34.3 \%$. The maximum standard deviation of 0.77 was obtained at a time of 20 minutes while the least deviation of 0.14 was observed at a time of 55 minutes. 


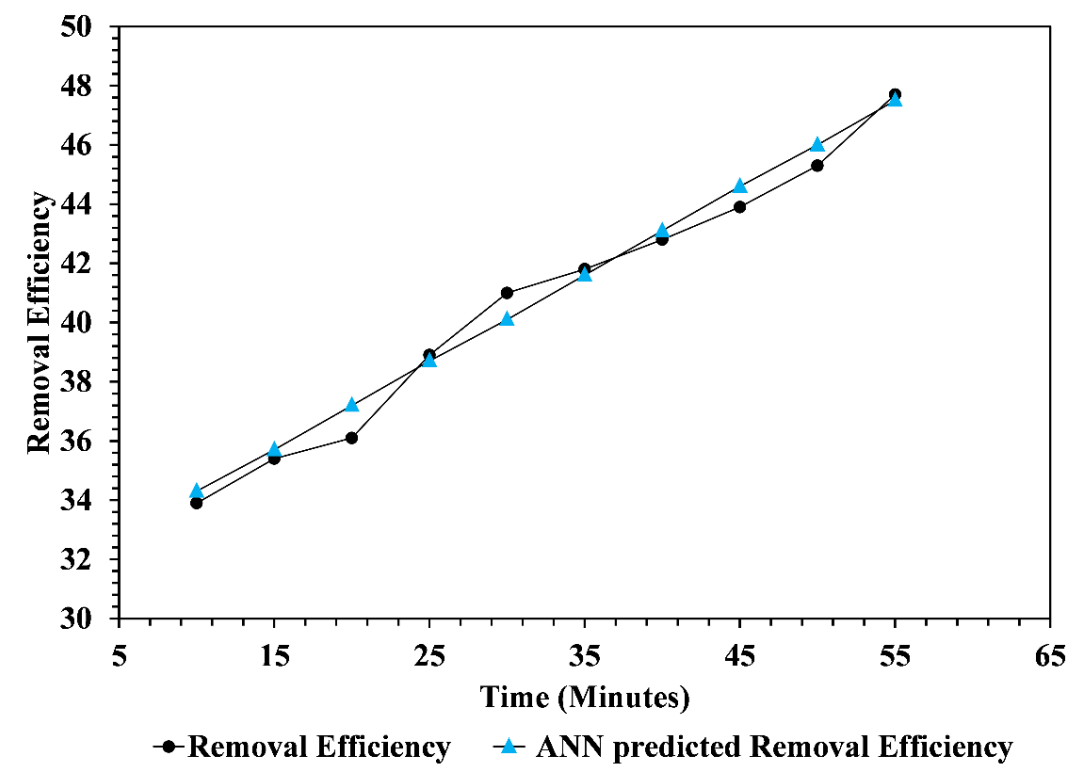

Figure 13: Effect of temperature on the removal efficiency of MO

\subsection{Adsorption Isotherm and kinetics}

To conclude the best fitting isotherm to any adsorption method, the frequently used equation is the linear regression. The obtained correlation coefficients are used to compare the applicability of isotherm equations. Langmuir, Freundlich, pseudo-first-order, and pseudosecond-order were implemented as described above. The linear representation of Langmuir and Freundlich models for both predicted and experimental model is shown in Fig. 14 (A-D), while the $\mathrm{R}^{2}$ values and constants are included in Table 3 . 

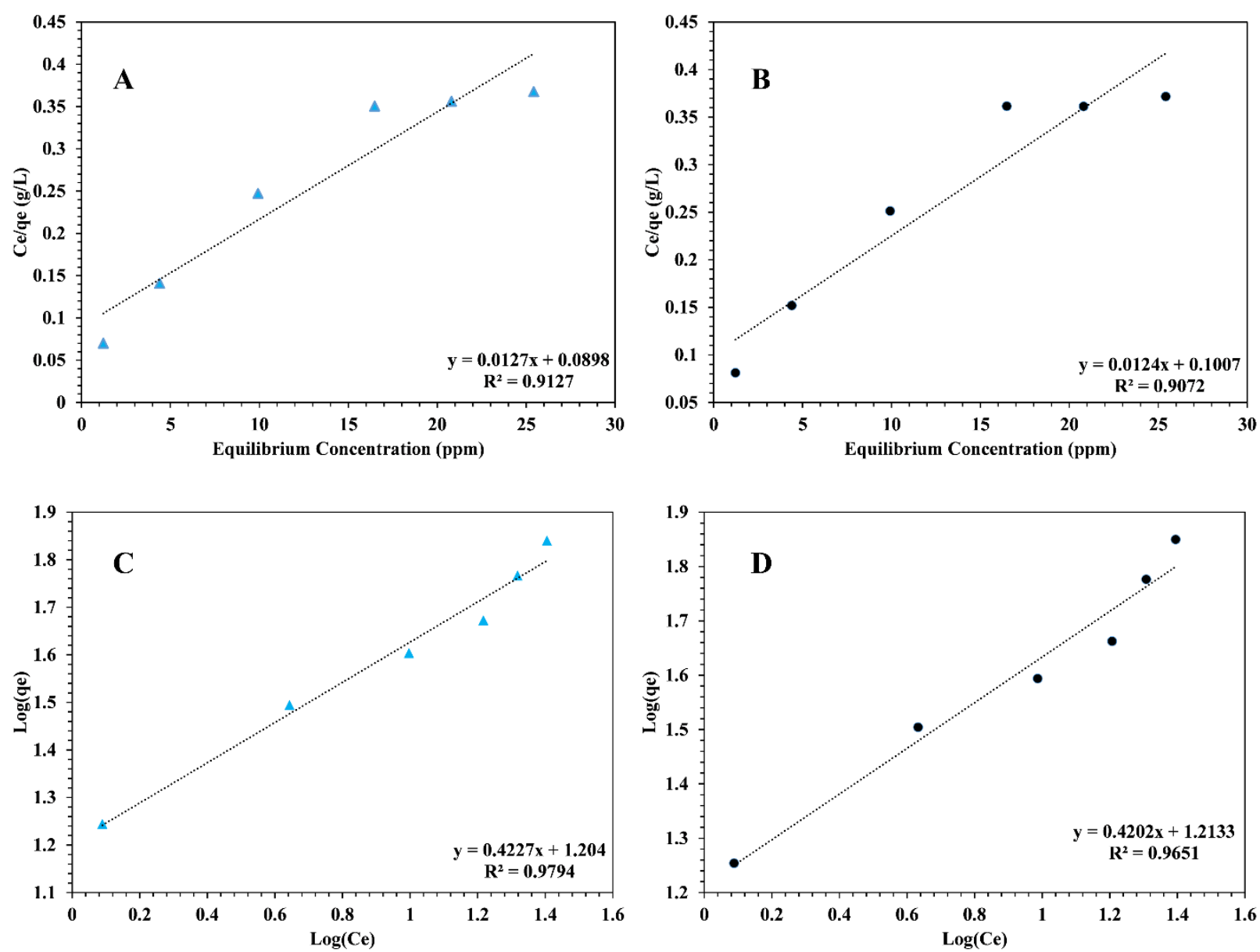

Figure 14: Isotherm study on removal efficiency of MO: (A) ANN Predicted Langmuir Model (B) Experimental Langmuir Model (C) ANN Predicted Freundlich Model (D)Experimental Freundlich Model

Table 3: Isotherm Models and Parameter Estimation for MO removal onto DSAC/Fe

\begin{tabular}{|l|l|l|l|}
\hline Isotherm Model & Type & Model Constants & $\mathbf{R}^{\mathbf{2}}$ \\
\hline Langmuir & Experimental & $\begin{array}{l}\mathrm{Q}_{0}=80.64 \mathrm{mg} / \mathrm{g} \\
\mathrm{B}=8.12 \mathrm{~L} / \mathrm{mg} \\
\mathrm{R}_{\mathrm{L}}=0.00408\end{array}$ & 0.9072 \\
& & Model & $\mathrm{Q}_{0}=78.74 \mathrm{mg} / \mathrm{g}$ \\
\cline { 2 - 4 } & ANN & 0.9127 \\
\hline
\end{tabular}




\begin{tabular}{|l|l|l|l|}
\hline & Predicted & $\begin{array}{l}\mathrm{B}=7.07 \mathrm{~L} / \mathrm{mg} \\
\mathrm{R}_{\mathrm{L}}=0.00469\end{array}$ & \\
\hline Freundlich & Experimental & $\begin{array}{l}\mathrm{K}_{\mathrm{F}}=3.36 \mathrm{~L} / \mathrm{g} \\
1 / \mathrm{n}=0.4202\end{array}$ & 0.9651 \\
& & MNN & $\mathrm{K}_{\mathrm{F}}=3.33 \mathrm{~L} / \mathrm{g}$ \\
$1 / \mathrm{n}=0.4227$ & 0.9794 \\
\cline { 2 - 4 } & Predicted & & \\
\hline
\end{tabular}

From Table 3 it is evident that the Freundlich isotherm model provides the highest $\mathrm{R}^{2}$ values (Experimental: 0.9651 and ANN Model predicted: 0.9794). Thus the adsorption assumes varied scattering of the surface energy of the active sites which also depends on the surface coverage. The values of $1 / \mathrm{n}$ and $\mathrm{K}_{\mathrm{F}}$ obtained from the Freundlich isotherm designate good adsorption capacity (Table 3). The Freundlich model adequately pronounces the adsorption of $\mathrm{MO}$ onto DSAC/Fe. From the isotherm study, it is evident that the adsorption of MO was done in multilayers on heterogeneous surfaces. Both experimental and model-predicted data agree with each other. The value of 1/n (Experimental: 0.4202 and ANN Model predicted: 0.4227 ) shows that the adsorption intensity attains a more non-uniform distribution.

The linear representation of pseudo-first-order and pseudo-second-order for both models predicted and experimental are shown in Fig. 15 (A-D), while the $\mathrm{R}^{2}$ values and constants are included in Table 4. It is clear from both the experimental and ANN model prediction that MO adsorption onto DSAC/Fe was best defined by the pseudo-second-order kinetic model. Table 4 illustrates that the correlation coefficient $\mathrm{R}^{2}$ for the pseudo-second-order kinetic (Experimental: 0.8945 and ANN Model predicted: 0.8749) equation was higher than pseudo-first-order (Experimental: 0.828 and ANN Model predicted: 0.7972 ) and that the calculated qe values were in a tolerable agreement with the corresponding experimental values. Both these results affirm that the adsorption data were well characterized by the pseudo-second-order kinetic model. Both experimental and model-predicted data agree with each other. The adsorption rate is proportionate to the square of the number of vacant adsorption sites. 

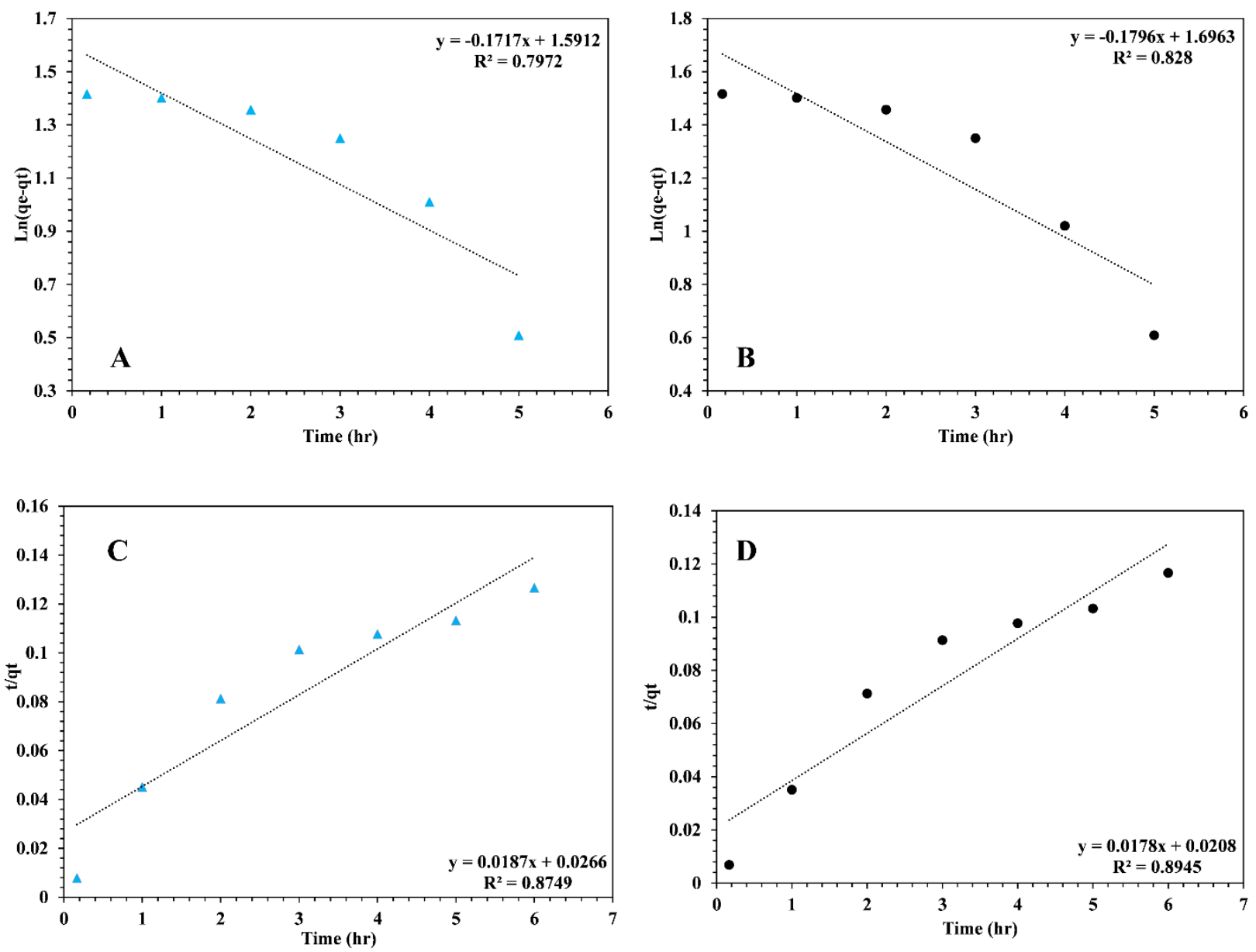

Figure 15: Kinetic study on removal efficiency of MO: (A) ANN Predicted Pseudo first order Kinetic Model (B) Experimental Pseudo first order Kinetic Model (C) ANN Predicted Pseudo second-order Kinetic Model (D)Experimental Pseudo second-order Kinetic Model 
Table 4: Kinetic Models and Parameter Estimation for MO removal onto DSAC/Fe

\begin{tabular}{|l|l|l|l|}
\hline \multicolumn{1}{|c|}{ Kinetic Model } & \multicolumn{1}{|c|}{ Type } & \multicolumn{1}{c|}{ Model Constants } & \multicolumn{1}{c|}{$\mathbf{R}^{2}$} \\
\hline Pseudo first order & Experimental & $\begin{array}{l}\mathrm{q}_{\mathrm{e}}=5.453 \mathrm{mg} / \mathrm{g} \\
\mathrm{k}_{1}=0.413 \mathrm{~h}^{-}\end{array}$ & 0.828 \\
& $\begin{array}{l}\text { ANN Model } \\
\mathrm{q}_{\mathrm{e}}=4.909 \mathrm{mg} / \mathrm{g} \\
\mathrm{k}_{1}=0.395 \mathrm{~h}^{-}\end{array}$ & 0.7972 \\
\hline Pseudo second order & Experimental & $\begin{array}{l}\mathrm{q}_{\mathrm{e}}=56.17 \mathrm{mg} / \mathrm{g} \\
\mathrm{k}_{2}=0.01523 \mathrm{~g} / \mathrm{mg} \mathrm{h}\end{array}$ & 0.8945 \\
& $\begin{array}{l}\text { ANN Model } \\
\mathrm{q}_{\mathrm{e}}=53.47 \mathrm{mg} / \mathrm{g} \\
\mathrm{k}_{2}=0.0119 \mathrm{~g} / \mathrm{mg} \mathrm{h}\end{array}$ & 0.8749 \\
\hline
\end{tabular}

Table 5: Comparative Analysis of prepared Activated Carbon

\begin{tabular}{|c|c|c|c|c|c|c|}
\hline $\begin{array}{c}\text { Source of } \\
\text { AC }\end{array}$ & $\operatorname{SSA}\left(\mathrm{m}^{2} / \mathrm{g}\right)$ & $\begin{array}{l}\text { Kinetic } \\
\text { Study }\end{array}$ & $\begin{array}{c}\text { Isotherm } \\
\text { Study }\end{array}$ & Dye & $\begin{array}{c}\text { Removal } \\
\text { Efficiency } \\
(\%)\end{array}$ & Reference \\
\hline $\begin{array}{c}\text { Digital } \\
\text { versatile } \\
\text { discs } \\
\text { (DVDs) }\end{array}$ & $\begin{array}{c}659 \\
(\mathrm{CNTs} / \mathrm{DVDs} \\
\mathrm{AC})\end{array}$ & $\begin{array}{l}\text { Pseudo- } \\
\text { second- } \\
\text { order }\end{array}$ & Langmuir & $\begin{array}{c}\text { Acid } \\
\text { Orange } 7\end{array}$ & 92.63 & $\begin{array}{c}\text { Noorimotl } \\
\text { agh et al. } \\
2019\end{array}$ \\
\hline $\begin{array}{c}\text { Iranian milk } \\
\text { vetch }\end{array}$ & 565 & $\begin{array}{l}\text { Pseudo- } \\
\text { second- } \\
\text { order }\end{array}$ & Langmuir & $\begin{array}{c}\text { Acid } \\
\text { orange } 7\end{array}$ & 87.90 & $\begin{array}{c}\text { Noorimotl } \\
\text { agh et al. } \\
2015\end{array}$ \\
\hline $\begin{array}{c}\text { Granular } \\
\text { activated } \\
\text { carbon } \\
\text { (GAC) } \\
\text { commercial }\end{array}$ & - & - & Langmuir & $\begin{array}{l}\text { Synthetic } \\
\text { arsenate }\end{array}$ & $\begin{array}{c}\text { close to } \\
100 \% \\
\text { with pH } \\
\text { less than } 6\end{array}$ & $\begin{array}{l}\text { Chang et } \\
\text { al. } 2010\end{array}$ \\
\hline $\begin{array}{c}\text { Commercial } \\
\text { AC }\end{array}$ & - & $\begin{array}{l}\text { Pseudo-- } \\
\text { second- }\end{array}$ & - & $\begin{array}{c}\text { Methylene } \\
\text { Blue }\end{array}$ & $98 \%$ & $\begin{array}{c}\text { Shah et al. } \\
2015\end{array}$ \\
\hline
\end{tabular}




\begin{tabular}{|c|c|c|c|c|c|c|}
\hline & & order & & & & \\
\hline $\begin{array}{l}\text { Synthetic } \\
\text { activated } \\
\text { carbon }\end{array}$ & - & $\begin{array}{l}\text { Pseudo- } \\
\text { second- } \\
\text { order }\end{array}$ & Langmuir & $\begin{array}{c}\text { Nitrate } \\
\text { adsorption }\end{array}$ & 56.7 & $\begin{array}{l}\text { Kalantary } \\
\text { et al. } 2016\end{array}$ \\
\hline $\begin{array}{l}\text { Spherical } \\
\text { granular } \\
\text { activated } \\
\text { carbon }\end{array}$ & 500 & $\begin{array}{l}\text { Pseudo- } \\
\text { first- } \\
\text { order }\end{array}$ & - & $\begin{array}{c}\text { Methylene } \\
\text { Blue }\end{array}$ & 90.0 & $\begin{array}{l}\text { Kadirova } \\
\text { et al. } 2014\end{array}$ \\
\hline Milk vetch & - & $\begin{array}{l}\text { Pseudo- } \\
\text { second- } \\
\text { order }\end{array}$ & Langmuir & $\begin{array}{c}\text { 4- } \\
\text { chlrorophe } \\
\text { nol }\end{array}$ & 89.52 & $\begin{array}{c}\text { Noorimotl } \\
\text { agh et al. } \\
2016\end{array}$ \\
\hline $\begin{array}{l}\text { Granular } \\
\text { activated } \\
\text { carbon } \\
\text { commercial }\end{array}$ & - & $\begin{array}{l}\text { Pseudo- } \\
\text { second- } \\
\text { order }\end{array}$ & Langmuir & $\begin{array}{c}\text { methylene } \\
\text { blue and } \\
\text { Acid } \\
\text { Orange } 7\end{array}$ & - & $\begin{array}{c}\text { Nourmora } \\
\text { di et al. } \\
2015\end{array}$ \\
\hline Date Stones & 738.65 & $\begin{array}{c}\text { Pseudo- } \\
\text { second- } \\
\text { order }\end{array}$ & $\begin{array}{c}\text { Freundlich } \\
\text { Isotherm }\end{array}$ & $\begin{array}{l}\text { Methyl } \\
\text { Orange }\end{array}$ & $\begin{array}{c}76.6 \text { at } 2 \\
p H\end{array}$ & $\begin{array}{c}\text { Present } \\
\text { Study }\end{array}$ \\
\hline
\end{tabular}

\section{Conclusion}

From the above study, it is evident that the activated carbon-containing oxides of iron can absorb methyl orange from wastewater. All the characterizations (SEM, XRD, FTIR, and BET) indicate the morphological and chemical changes of the prepared activated carbon. The SSA of DSAC was $1031.46 \mathrm{~m} 2 / \mathrm{g}$ while that of DSAC/Fe was $738.65 \mathrm{~m} 2 / \mathrm{g}$. Although, there was a reduction in surface area the, removal efficiency of DSAC/Fe was better due to the presence of iron oxides. The ANN model developed in the study can predict almost accurately the removal efficiency of MO dye in any parameter condition. From the parameter study, both experimental and modelpredicted values illustrate that the removal efficiency decreases with the increase in initial dye concentration. The highest removal was obtained at $2 \mathrm{pH}$. The adsorption process follows the Freundlich isotherm and pseudo-second-order kinetic model. The adsorption rate is proportionate to the square of the number of vacant adsorption sites. From the thermodynamic study, the 
positive worth of $\Delta \mathrm{H}^{\circ}$ indicates the energy-absorbing nature of the surface assimilation method and the process is endothermic in nature. The low values of each $\Delta \mathrm{G}^{\circ}(-200$ to $0 \mathrm{~kJ} / \mathrm{mol})$ and $\Delta \mathrm{H}^{\circ}$ correspond to physical surface assimilation.

\section{Acknowledgment}

The authors would like to acknowledge the Polymer Science and Technology Department, University of Calcutta, India to carry out the experiment. This research did not receive any specific grant from funding agencies in the public, commercial or not-for-profit sectors.

\section{References:}

M. S. Tsuboy, J. P. F. Angeli, M. S. Mantovani, S. Knasmueller, G. A. Umbuzeiro and L. R. Ribeiro, 2007,“Genotoxic, Mutagenic and Cytotoxic Effects of the Commercial Dye CI Disperse Blue 291 in the Human Hepatic Cell Line HepG2," Toxicology in Vitro, Vol. 21, No. 8, pp. 1650-1655.

S. Vinitnantharat, W. Chartthe and A. Pinisakul, 2008, "Toxicity of Reactive Red 141 and Basic Red 14 to Algae and Waterfleas," Water Science and Technology, Vol. 58, No. 6, pp. 11931198.

S. Mitra, Tirthankar Mukherjee, 2018, "Novel Low Cost Adsorbent for the Removal of Rhodamine B Dye from Wastewater", International Journal of Engineering Research And Management, ISSN: 2349- 2058, Volume-05, Issue-07.

Ghaedi, Abdol Mohammad, and Azam Vafaei, 2017, "Applications of artificial neural networks for adsorption removal of dyes from aqueous solution: a review." Advances in colloid and interface science $245: 20-39$.

Alslaibi, Tamer M., Ismail Abustan, MohdAzmier Ahmad, and Ahmad Abu Foul. 2013, "Cadmium removal from aqueous solution using microwaved olive stone activated carbon." Journal of Environmental Chemical Engineering 1, no. 3 : 589-599. 
Noorimotlagh, Z., Darvishi Cheshmeh Soltani, R., Shams Khorramabadi, G., Godini, H., \& Almasian, M. (2016). Performance of wastewater sludge modified with zinc oxide nanoparticles in the removal of methylene blue from aqueous solutions. Desalination and Water Treatment, 57(4), 1684-1692.

Jaafarzadeh, N., Baboli, Z., Noorimotlagh, Z., Martinez, S. S., Ahmadi, M., Alavi, S., \& Mirzaee, S. A. (2019). Efficient adsorption of bisphenol A from aqueous solutions using lowcost activated carbons produced from natural and synthetic carbonaceous materials. Desalination and Water Treatment, 154, 177-187.

Mirzaei, N., Ghaffari, H. R., Sharafi, K., Velayati, A., Hoseindoost, G., Rezaei, S., ... \& Dindarloo, K. (2017). Modified natural zeolite using ammonium quaternary based material for Acid red 18 removal from aqueous solution. Journal of environmental chemical engineering, 5(4), 3151-3160.

E.N. El-Qada, S.J. Allen, G.M. Walker, 2006, “Adsorption of Methylene Blue onto activated carbon produced from steam activated bituminous coal: a study of equilibrium adsorption isotherm”, Chem. Eng. J. 124, 103-110.

Al-Ghouti, M.A., Li, J., Salamh, Y., Al-Laqtah, N., Walker, G. and Ahmad, M.N., 2010. "Adsorption mechanisms of removing heavy metals and dyes from aqueous solution using date pits solid adsorbent”. Journal of hazardous materials, 176(1-3), pp.510-520.

Ozbelge, T. A., O. H. Ozbeze, and S. Z. Baskaya, 2002, "Heavy metal adsorption onto agrobased waste materials." Chem. Eng. Process 41 : 719-730.

Pasalari, H., Ghaffari, H. R., Mahvi, A. H., Pourshabanian, M., \& Azari, A. (2017). Activated carbon derived from date stone as natural adsorbent for phenol removal from aqueous solution. DESALINATION AND WATER TREATMENT, 72, 406-417. 
M. Ghaedi, A. Hassanzadeh, S. NasiriKokhdan, 2011, "Multiwalled carbon nanotubes as adsorbents for the kinetic and equilibrium study of the removal of Alizarin Red S and Morin", J. Chem. Eng. Data 56, 2511-2520.

Mesdaghinia, A., Azari, A., Nodehi, R. N., Yaghmaeian, K., Bharti, A. K., Agarwal, S., ... \& Sharafi, K. (2017). Removal of phthalate esters (PAEs) by zeolite/Fe3O4: Investigation on the magnetic adsorption separation, catalytic degradation and toxicity bioassay. Journal of Molecular Liquids, 233, 378-390.

Azari, A., Mahmoudian, M. H., Niari, M. H., Eş, I., Dehganifard, E., Kiani, A., ... \& Khaneghah, A. M. (2019). Rapid and efficient ultrasonic assisted adsorption of diethyl phthalate onto FeIIFe2IIIO4@ GO: ANN-GA and RSM-DF modeling, isotherm, kinetic and mechanism study. Microchemical Journal, 150, 104144.

T. Mukherjee, S.K. Ghosh and M. Rahaman, 2018, "Determining The Quality Of Activated Carbon Using L16 Taguchi Method Through Waste Tyre Recycling", Springer Book Volume 3, Waste Water Recycling and Management. (DOI:10.1007/978-981-13-2619-6)

T. Mukherjee, M. Rahaman, April 2018, "Development of ANN based model for adsorption of hazardous dye in Waste Tire Derived Activated Carbon", International Journal of Innovative Research and Studies, ISSN No.: 2319-9725, Volume 8, Issue IV.

M. Roosta, M. Ghaedi, N. Shokri, A. Daneshfar, R. Sahraei, A. Asghari, 2014, "Optimization of the combined ultrasonic assisted/adsorption method for the removal of malachite green by gold nanoparticles loaded on activated carbon: Experimental design, Spectrochim". Acta - Part A Mol. Biomol. Spectrosc. 118, 55-65.

D. Kalyanmoy,1996, "Optimizations for Engineering Design - Algorithm and Examples", Prentice Hall of India, New Delhi, pp. 290-333. 
Nia, R. Hosseini, M. Ghaedi, and A. M. Ghaedi. 2014, "Modeling of reactive orange 12 (RO 12) adsorption onto gold nanoparticle-activated carbon using artificial neural network optimization based on an imperialist competitive algorithm." Journal of Molecular Liquids 195: 219-229.

Karimi, H., and M. Ghaedi. 2014, "Application of artificial neural network and genetic algorithm to modeling and optimization of removal of methylene blue using activated carbon." Journal of Industrial and Engineering Chemistry 20, no. 4: 2471-2476.

Azari, A., Gholami, M., Torkshavand, Z., Yari, A., Ahmadi, E., \& Kakavandi, B. (2015). Evaluation of basic violet 16 adsorption from aqueous solution by magnetic zero valent ironactivated carbon nanocomposite using response surface method: isotherm and kinetic studies. Journal of Mazandaran University of Medical Sciences, 24(121), 333-347.

Zeinali N, Ghaedi M, Shafie G.2014,"Competitive adsorption of methylene blue and brilliant green onto graphite oxide nano-particle following: derivative spectrophotometric and principal component-artificial neural network model methods for their simultaneous determination". Journal of Industrial and Engineering Chemistry;20:3550-8.

Kakavandi, Babak, Roshanak Rezaei Kalantary, Mahdi Farzadkia, Amir Hossein Mahvi, Ali Esrafili, Ali Azari, Ahmad Reza Yari, and Allah Bakhsh Javid. 2014, "Enhanced chromium (VI) removal using activated carbon modified by zero valent iron and silver bimetallic nanoparticles." Journal of environmental health science and engineering 12 , no. $1: 115$.

N. Hoda, E. Bayram, E. Ayranci, 2006, "Kinetic and equilibrium studies on the removal of acid dyes from aqueous solutions by adsorption onto activated carbon cloth", J. Hazard. Mater. B137 344-351.

K.V. Kumar, K. Porkodi, 2009, "Modelling the solid-liquid adsorption processes using artificial neural networks trained by pseudo second order kinetics", Chem. Eng. J. 148 , 20-25. 
Shweta Mitra, T. Mukherjee, August, 2018, "Novel Adsorbent Using Nanoparticle Loaded Chitosan-Alginate Beads for $\mathrm{Pb}$ (II) Removal from Waste Water: Adsorption Isotherm Study”, International Journal Of Innovation Science And Research, Vol.7, No, 08, pp.1243-1247.

C.W. Ahn, 2006, "Advances in Evolutionary Algorithms: Theory Design and Practice", Springer Verlag.

D.C. Montgomery,2007, “Design and Analysis of Experiments”, 7th ed., John Wiley \& Sons, Inc., Hoboken, NJ.

Y. Zhang, J. Xu, Z. Yuan, H. Xu, Q. Yu, 2010, “Artificial neural network-genetic algorithm based optimization for the immobilization of cellulose on the smart polymer" Eudragit L-100, Biores. Technol. 101, 3153-3158.

A. Carlos, P. Filho, R.M. Filho,2010,"Hybrid training approach for artificial neural networks using genetic algorithms for rate of reaction estimation: application to industrial methanol oxidation to formaldehyde on silver catalyst", Chem. Eng. J. 157, 501-508.

A.R. Soleymani, J. Saiena, H. Bayat, 2011, “Artificial neural networks developed for prediction of dye decolorization efficiency with UV/K2S2O8 process", Chem. Eng. J. 170, 29-35.

H. Karimi, F. Yousefi, M.R. Rahimi, 2011, "Correlation of viscosity in nanofluids using genetic algorithm-neural network (GA-NN)", Heat Mass Transf. 47, 1417-1425.

H. Karimi, F. Yousefi, 2012, “Application of artificial neural network-genetic algorithm (ANNGA) to correlation of density in nanofluids", Fluid Phase Equilibr. 336, 79-83.

C. Sivapathasekaran, S. Mukherjee, A. Ray, A. Gupta, R. Sen, 2010, "Artificial neural network modeling and genetic algorithm based medium optimization for the improved production of marine biosurfactant", Bioresour. Technol. 101, 2884-2887. 
M. Roosta, M. Ghaedi, A. Daneshfar, R. Sahraei, A. Asghari, 2014, "Optimization of the ultrasonic assisted removal of methylene blue by gold nanoparticles loaded on activated carbon using experimental design methodology", Ultrason. Sonochem. 21, 242-252.

W.H. Li, Q.Y. Yue, B.Y. Gao, Z.H. Ma, Y.J. Li, H.X. Zhao, 2011, "Preparation and utilization of sludge-based activated carbon for the adsorption of dyes from aqueous solutions", Chem. Eng. J. $171,320-327$.

T. Mukherjee, M. Rahaman, April 2018, "Process Optimization of removal of Methylene Blue using Waste-Derived Adsorbent”, International journal of Engineering and Techniques, ISSN No.: 2395-1303, Volume 4, Issue II.

R. Soleimani, N.A. Shoushtari, B. Mirza, A. Salahi, 2012,"Experimental investigation, modeling and optimization of membrane separation using artificial neural network and multi-objective optimization using genetic algorithm”, Chem. Eng. Res. Des. 91 ,883-903.

V.K. Gupta, S.K. Srivastava, D. Mohan, 1997,“Equilibrium uptake, sorption dynamics, process optimization and column operations for the removal and recovery of malachite green from waste water using activated carbon and activated slag”, Ind. Eng. Chem. Res. $36,2207-2218$.

Shweta Mitra, T. Mukherjee, August 2018, "Nanoparticle Loaded Chitosan-Alginate Beads as Potential Adsorbent for Pb (II) Removal from Waste Water: A Parameter Study”, International Journal of Innovative Research \& Studies, ISSN NO: 2319-9725, Volume 8, Issue VIII.

K.K.H. Choy, J.F. Porter, G. McKay, 2004, "Intraparticle diffusion in single and multicomponent acid dye adsorption from wastewater onto carbon”, Chem. Eng. J. $103,133-$ 145.

Kalantary, R. R., Azari, A., Esrafili, A., Yaghmaeian, K., Moradi, M., \& Sharafi, K. (2016). The survey of Malathion removal using magnetic graphene oxide nanocomposite as a novel 
adsorbent: thermodynamics, isotherms, and kinetic study.Desalination and Water Treatment, 57(58), 28460-28473.

Bellifa, A., Makhlouf, M. and Boumila, Z.H., 2017. "Comparative study of the adsorption of methyl orange by bentonite and activated carbon". ActaPhysicaPolinica A, 132, p.466.

H. El Bakouri, J. Usero, J. Morillo, A. Ouassini,2009,“Adsorptive features of acid-treated olive stones for drin pesticides: equilibrium, kinetic and thermodynamic modeling studies", Bioresour. Technol. $100,4147-4155$.

Noorimotlagh, Z., Mirzaee, S. A., Martinez, S. S., Alavi, S., Ahmadi, M., \& Jaafarzadeh, N. (2019). Adsorption of textile dye in activated carbons prepared from DVD and CD wastes modified with multi-wall carbon nanotubes: Equilibrium isotherms, kinetics and thermodynamic study. Chemical Engineering Research and Design, 141, 290-301.

Noorimotlagh, Z., Soltani, R. D. C., Khataee, A. R., Shahriyar, S., \& Nourmoradi, H. (2014). Adsorption of a textile dye in aqueous phase using mesoporous activated carbon prepared from Iranian milk vetch. Journal of the Taiwan Institute of Chemical Engineers, 45(4), 1783-1791.

Chang, Q., Lin, W., \& Ying, W. C. (2010). Preparation of iron-impregnated granular activated carbon for arsenic removal from drinking water. Journal of Hazardous Materials, 184(1-3), 515522.

Shah, I., Adnan, R., Ngah, W. S. W., \& Mohamed, N. (2015). Iron impregnated activated carbon as an efficient adsorbent for the removal of methylene blue: regeneration and kinetics studies. PloS one, 10(4), e0122603.

Rezaei Kalantary, R., Dehghanifard, E., Mohseni-Bandpi, A., Rezaei, L., Esrafili, A., Kakavandi, B., \& Azari, A. (2016). Nitrate adsorption by synthetic activated carbon magnetic nanoparticles: kinetics, isotherms and thermodynamic studies. Desalination and Water Treatment, 57(35), 16445-16455.

Kadirova, Z. C., Hojamberdiev, M., Katsumata, K. I., Isobe, T., Matsushita, N., Nakajima, A., ... \& Okada, K. (2014). Preparation of iron oxide-impregnated spherical granular activated carbon- 
carbon composite and its photocatalytic removal of methylene blue in the presence of oxalic acid. Journal of Environmental Science and Health, Part A, 49(7), 763-769.

Noorimotlagh, Z., Shahriyar, S., Darvishi Cheshmeh Soltani, R., \& Tajik, R. (2016). Optimized adsorption of 4-chlorophenol onto activated carbon derived from milk vetch utilizing response surface methodology. Desalination and Water Treatment, 57(30), 14213-14226.

Nourmoradi, H., Ghiasvand, A. R., \& Noorimotlagh, Z. (2015). Removal of methylene blue and acid orange 7 from aqueous solutions by activated carbon coated with zinc oxide ( $\mathrm{ZnO})$ nanoparticles: equilibrium, kinetic, and thermodynamic study.Desalination and water treatment, 55(1), 252-262. 